\title{
Additional records of the chironomid midges from the Ryukyu Islands, southern Japan (Diptera, Chironomidae)
}

\author{
Manabu SASA* and Hideo Hasegawa** \\ * Toyama Medical and Pharmaceutical University, Sugitani, Toyama 930-01, Japan \\ ** Department of Parasitology, School of Medicine, University of the Ryukyus, \\ Nishihara-cho, Okinawa 903-01, Japan
}

(Received: October 14, 1987)

Key words: Chironomidae, Ryukyu Islands, new genus, new species.

\begin{abstract}
In addition to the total of 26 chironomid species of the tribe Chironomini recorded by Sasa and Hasegawa (1983) and Hasegawa and Sasa (1987), 16 more species belonging to the other tribes of the family Chironomidae from the Ryukyu Islands are recorded in the present paper, namely 4 species of Tanytarsini, 10 species of Orthocladiinae, and 2 species of Tanypodinae. Among them, 10 are described as new species. A new genus, Okinawayusurika, is established with $O$. otsurui, sp. nov. as the genotype. In addition, Smittia pratorum is described as a new record from Japan, and new scientific names are given for 3 species of the genus Polypedilum which were listed in our previous paper without designating scientific names.
\end{abstract}

\section{INTRODUCTION}

Collections of adult as well as larval chironomid midges were carried out during the period from December 1981 to February 1982 on the three main islands of the Ryukyu Archipelago, Okinawa, Miyako and Ishigaki. The adults were collected from their resting places or while swarming in the air with insect net. The larvae breeding in the bottom of sewage ditches, eutrophicated ponds, or some clean mountain streams were collected together with the bottom sediments, and were reared in the laboratory to obtain the adult midges for the taxonomic studies. Among the chironomids collected and identi-

* 佐々 学：富山医科薬科大学（干930-01 富山市 杉谷 2630)

** 長谷川英男：琉球大学医学部寄生虫学教室 (干903-01 沖繩県西原町) fied, 26 species belonging to the tribe Chironomini of the subfamily Chironominae were recorded and described in the first paper by Sasa and Hasegawa (1983). In the second paper by Hasegawa and Sasa (1987), the pupae of 17 species and the larvae of 8 species among them were described, and new scientific names were given for 4 species recorded in the first report without giving scientific names. The present paper deals mainly with the records and descriptions of the species belonging to the other tribes or subfamilies of the family Chironomidae collected or reared at the same time as the specimens recorded in our previous papers. In addition, new scientific names are given for 3 species of the genus Polypedilum, which were already listed in our previous paper without designating scientific names.

The methods of collection, preservation and mounting the chironomid specimens are the same as described in our first report. In 
addition to the standard measurement items used in the previous papers, the following measurements are added in the present paper. AHR (antennal hair ratio), the length of longest antennal hairs on the last short antennal segment divided by the combined length of the flagellar segment of antenna; $R R$ (radius ratio), the distance between ends of $R 1$ and $R 2+3$ divided by the distance between ends of $\mathrm{R} 1$ and $\mathrm{R} 4+5$; VR (the venarum ratio), the distance between wing base (tip of arculus) and $\mathrm{fCu}$ divided by the distance between wing base and $r-m$; $\mathrm{R} / \mathrm{Cu}$, the distance between wing base and end of $\mathrm{R} 4+5$ divided by the distance between wing base and end of $\mathrm{Cu} 1$.

Most of the specimens (those with the mark "No. A") used in the present study, including all holotypes and some paratypes, are provisionally preserved in the Toyama Medical and Pharmaceutical University. Some paratypes and other specimens (those with the mark "ChT") are deposited in the Department of Parasitology, School of Medicine, University of the Ryukyus.

\section{Polypedilum tananense Sasa et Hasegawa, sp. nov.}

\#21. Polypedilum sp. (Tanane-yusurika) of Sasa and Hasegawa, 1983, Jpn. J. Sanit. Zool. 34: 326, Fig. 4-Q.

Holotype: male, No. A 64:41. Paratypes: 2 males, No. A 64:42, 43. All emerged from a bottom mud collected from a clean stream at Tanane, Miyako Island, on February 2, 1982. The morphology of male and female as well as the distinguishing characters from the related species were given in the previous paper. It belongs to the subgenus Tripodura Townes, 1945, and can be differentiated from the previously known Japanese species of this group by the following key.

1. Wing without dark marks; ninth tergite with narrow and apically pointed lateral tubercles; AR 1.46-1.57, fLR 1.46-1.52, fBR $3.0-3.2 \ldots \ldots$...... scalaenum (Schrank, 1803) of Sasa (1985a, p. 7) Wing with dark marks ......... 2

2. Wing with one dark patch in cell R-M (between veins $R 4+5$ and $M$ ), and another dark patch in cell $\mathrm{Cu}$ (between $\mathrm{Cu} 1$ and $\mathrm{Cu} 2) \ldots \ldots \ldots \ldots \ldots . \ldots$
- Wing with two or more dark patches in cell R-M and also in cell $\mathrm{Cu} \ldots \ldots 7$

3. Ninth tergite without lateral processes flanking anal point; anal point wide and short; dorsal appendage with a beak-like inner process and with 2 long setae on posterior margin .............. ...... japonicum (Tokunaga, 1938)

- Ninth tergite with a pair of lateral tubercles flanking anal point ....... 4

4. Anal point narrow, slender and parallelsided; AR usually $0.6-0.8$; body largely yellow ............... 5

-. Anal point short and stout; AR usually larger than $1.0 \ldots \ldots \ldots \ldots \ldots$

5. Dorsal appendage with only one long posterior seta; lateral processes flanking anal point long, narrow and sharply pointed; AR 0.58-0.66 ... unifascium (Tokunaga, 1938) of Sasa (1980, p. 32)

-. Dorsal appendage with 4 long posterior setae; lateral processes flanking anal point low and roughly rectangular; $\mathrm{AR}$ $0.81-0.83 \ldots \ldots \ldots \ldots \ldots \ldots \ldots$. ... miyakoense Hasegawa et Sasa, 1987

6. Body largely pale yellow, dark marks on wing rather faint; anal point stout and parallel-sided; lateral processes flanking anal point low and very wide; dorsal appendage much longer than wide, with only one long posterior seta; WL 1.46$1.62 \mathrm{~mm}$, AR 1.13-1.15, fLR 1.92-2.06, fBR 2.9-3.3 ..... tananense sp. nov.

-. Body largely dark brown, dark marks on wing much darker; anal point narrow at base and apically expanded, sometimes like figure $\mathrm{T}$; lateral processes flanking anal point long, narrow and apically pointed; dorsal appendage nearly as wide as long, with 3-6 long posterior setae; WL $1.57-1.70 \mathrm{~mm}$, AR 1.14-1.38, fLR 1.87-2.00, fBR 3.0-3.3 ... tamahinoense Sasa et Ichimori, 1983

7. Wing with 2 dark patches in cell R-M; dorsal appendage long and finger-like, not expanded apically and with only one long seta; lateral processes flanking anal point low and obtuse; AR about 1.8, fLR about 2.0 (after Tokunaga, 1938) . . sagittiferum (Tokunaga, 1938)

- Wing with 3 dark patches in cell R-M; dorsal appendage shorter, wider and apically expanded, with 3-5 long setae 
$\ldots \ldots \ldots \ldots \ldots \ldots \ldots$

8. Anal point constricted at base and apically expanded; lateral processes flanking anal point acutely produced; dorsal appendage with a long lateral seta, and 4 shorter inner setae; AR about 2.0, fLR about 1.8 (after Tokunaga, 1938, p. 337)

decematoguttatum (Tokunaga, 1938)

- Anal point long, narrow, widest at base and apically pointed; ninth tergite without lateral processes flanking anal point; dorsal appendage short, apically expanded and with a beak-like inner process, with 4 long setae on posterior margin and 3 shorter setae on inner margin; AR about 1.5, fLR about 1.8 ....... masudai (Tokunaga, 1938)

\section{Polypedilum kunigamiense Sasa et Hasegawa. sp. nov.}

\#23. Polypedilum sp. (Kunigami-yusurika) of Sasa and Hasegawa, 1983, Jpn. J. Sanit. Zool. 34:328, Fig. 5-R.

This species belongs to the nubeculosum group of genus Polypedilum, and has the dorsal appendage composed of a low and broad base bearing long inner setae, and a horn-like distal blade bearing a long lateral seta. Among the previously known species of this group, it is most closely related to $P$. albicorne (Meigen, 1838) recorded from Europe and redescribed by Pinder (1978, p. 138, Fig. 170A), but both differ from each other in the shape and structure of anal point and dorsal appendage. as pointed out in our previous paper.

Type specimens. Holotype: male, No. A 64:71. Paratypes: 2 males and 3 females, Nos. A 64:72-76. All emerged from fallen leaves in the bottom of a clean mountain stream at Benoki, Kunigami-son. northern Okinawa, on December 10, 1981.

\section{Polypedilum benokiense Sasa et Hasegawa. sp. nov.}

\#24. Polypedilum sp. (Benoki-yusurika) of Sasa and Hasegawa, 1983, Jpn. J. Sanit. Zool. 34: 328, Fig. 5-S.

This is also a member of the nubeculosum group of genus Polypedilum and is most closely related to $P$. arundineti (Goetghebuer, 1921), which was originally described from Europe and was also recorded by Sasa (1985a, p. 6) from Hokkaido, northern Japan, but in the present species gonostylus is much longer and narrower, $\mathrm{AR}$ is smaller ( 0.70 in the present species, 1.55 in arundineti), while fLR is 1.84 and larger than 1.6 of arundineti.

Type specimen. Holotype: male, No. A $64: 47$, emerged from the same bottom sample as the last species, collected in the bottom of a mountain stream at Benoki, northern Okinawa, on December 10, 1981.

\section{Tanytarsus kitaokinawanus Sasa et Hasegawa, sp. nov.}

(Fig. 1-a-n)

A male and a female emerged from fallen leaves collected in the bottom of a mountain stream at Benoki, northern Okinawa, on December 10, 1981.

Male. BL $1.94 \mathrm{~mm}$, WL $1.18 \mathrm{~mm}$. Body almost entirely pale yellow, Scutal stripes and postnotum slightly brownish. Eyes bare, ER 0.90. Frontal tubercles absent. Antenna with 13 flagellar segments, AR 0.67, AHR 0.48 . so $8: 8$, cl 12 , pn $0: 0$, dm 8 , dl $6: 6$, pa $1: 1$, sc 4 . Wing (Fig. 1-d) cneiform, macrotrichiae are distributed rather sparsely on distal half of wing membrane and on veins $\mathrm{R} 1, \mathrm{R} 4+5, \mathrm{M}, \mathrm{Cu} 1, \mathrm{Cu} 2$ and $\mathrm{An}$. RR 0.49, VR 1.33, R/Cu 1.08. fLR 2.67, mLR 0.57, hLR 0.67, fTR 0.39, fBR 2.8. $\mathrm{mBR}$ 3.5, hBR 3.6. Tips of tibiae in Fig. 1-e, f. g. Pulvilli absent.

Hypopygium in Fig. 1-h. Bands of ninth tergite united, and not produced caudally towards the middle. Anal point (Fig. 1-i) wide and short, with lateral ridges, and 5 spine clusters distributed roughly in double rows, and with 4 short setae at base and 2 lateral setae on both sides. Dorsal appendage (Fig. 1-j, k, 1) roughly triangular, widest at base and rather pointed apically, with 4 lateral, one subapical, 2 inner setae, and one basal seta arising on a small tubercle. Digitus blade-like, slightly curved inwards, almost parallel-sided and with rounded apex, longer than dorsal appendage and largely extending beyond its inner margin. Ventral appendage short and stout, bearing 7 recurved setae on 


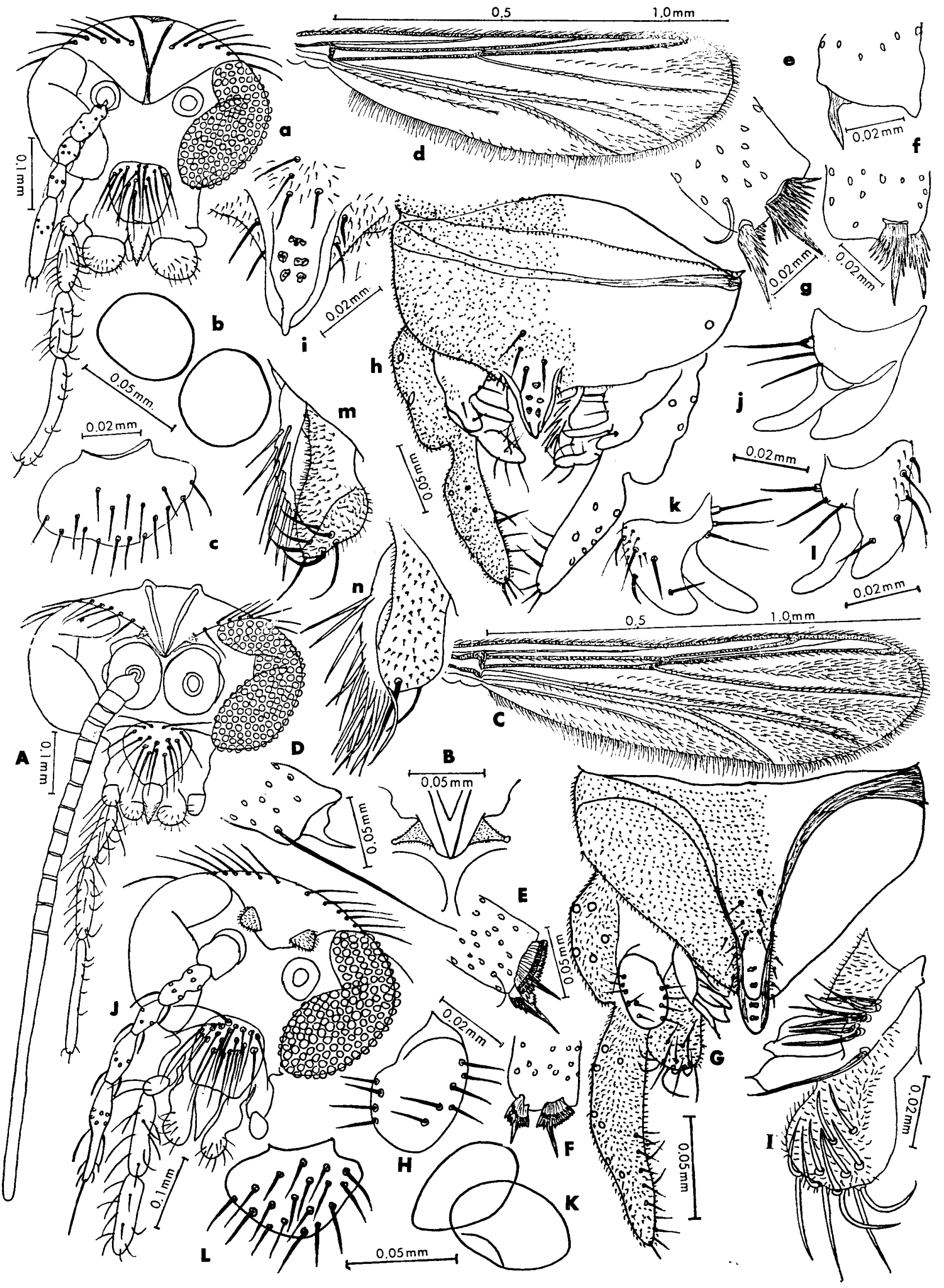

Fig. 1 
dorsal side and 3 caudally directed setae on the ventral side of the apical portion. Median appendage (appendage 2-a) long, apical setae extending beyond tip of ventral appendage, bearing numerous narrow and simple setae (Fig. 1-m, n). Gonostylus widest at about middle and smoothly tapering towards apex, with relatively long inner setae in the apical portion.

Female. Body length $1.66 \mathrm{~mm}$, wing length $1.21 \mathrm{~mm}$. Body largely pale yellow, scutal stripes reddish yellow. Head in Fig. 1-a. Eyes reniform, inner margin concave but without dorsomedial projection, ER 0.91 . Antenna composed of a pedicel and 4 flagellar segments $(70,43,50,120 \mu \mathrm{m}), \mathrm{AR}$ 0.74 , AHR 0.61, last segment with 3 fine sensory setae near apex but without long apical seta. Palp 4 segmented. so $6: 6$, cl 15, pn $0, \mathrm{dm} 12$, dl $12: 12$, pa $1: 1$, sc 4 . Wing with macrotrichiae more numerous and widespread than in male, venation as in male. RR 0.53, VR 1.35, fLR 2.74, mLR 0.58, hLR 0.64, fTR 0.42, fBR 2.8, mBR 3.3, hBR 3.9. Pulvilli absent. Spermathecae (Fig. 1-b) small, both roughly globular, $37 \times 38$ and $34 \times 36 \mu \mathrm{m}$. Cercus (Fig. $1-\mathrm{c}$ ) also small, $38 \mu \mathrm{m}$ long and $60 \mu \mathrm{m}$ wide.

Type specimens. Holotype: male, No. A 64:70a. Paratype: female, No. A 64:73b. Both emerged from a sample collected at Benoki, Kunigami-son, northern Okinawa.

Remarks. This species is somewhat related to Tanytarsus lestagei Goetghebuer described by various authors from Europe in that anal point is wide, short and bearing several spine clusters, and median appendage is very long and extending beyond tip of ventral appendage, but differs from the latter in that anal tergite bands are united in the middle (separated in lestagei), and that dorsal appendage is triangular (elongate oval in lestagei). Among members of this genus recorded from Japan, the present species is closest to the one noted by Sasa (1985a, p. 9, Fig. 5) as Tanytarsus sp. "utonai" from Lake Utonai (Hokkaido) in the structure of hypopygium, especially in the shape of dorsal appendage and digitus, but they differ from each other in body coloration (dark brown in "utonai"), in the number of spine clusters on anal point (11 in "utonai", only 5 in the present species), and in the relative length of median appendage (long but not extending beyond tip of ventral appendage in "utonai"), and also in the structure of anal tergite bands (separated in "utonai"). Frontal tubercles are absent both in the present species and in "utonai," while they are present and rather conspicuous in all of the three following species of Tanytarsus being recorded from Okinawa.

\section{Tanytarsus miyakoflavus Sasa et Hasegawa, sp. nov.}

(Fig. 1-A-L)

Many males and females emerged from bottom sediments collected in a small unpolluted stream in a plantation on Miyako Island, on February 2, 1982; 13 males and 10 females among them were mounted on slides for morphological study.

Male. BL 2.35-2.75 (2.51 in average of 12) $\mathrm{mm}$, WL 1.47-1.75 (1.62) $\mathrm{mm}$. Ground color of scutum yellow, scutal stripes brownish yellow, scutellum pale yellow, postnotum brownish yellow, abdominal tergites yellow, halteres white, legs brownish yellow. Head in Fig. 1-A. Eyes bare, each with a long dorsomedial projection, ER 0.54-0.77 (0.65) (smaller than in the preceding species). Frontal tubercles (Fig. 1-B) 20-33 (27) $\mu \mathrm{m}$ high, $10-18$ (14) $\mu \mathrm{m}$ wide, and 52-73 (61) $\mu \mathrm{m}$ apart from each other. Antenna with 13 flagellar segments, AR 0.86-1.11 (0.96), AHR 0.42-0.49 (0.47), so 6-9 (7.3), cl 1216 (14.3), pn absent, $\mathrm{dm} 11-16$ (13.3), dl

Fig. 1 Tanytarsus kitaokinawanus, sp. nov. and Tanytarsus miyakoflavus, sp. nov:

Tanytarsus kitaokinawanus, sp. nov. Female: a, head; b, spermathecae; c, cercus; Male: $\mathrm{d}$, wing; $\mathrm{e}$, tip of front tibia; $\mathrm{f}$, tip of middle tibia; $\mathrm{g}$, tip of hind tibia; $\mathrm{h}$, hypopygium; $\mathrm{i}$, anal point; $\mathrm{j}$, dorsal appendage and digitus, ventral view; $\mathrm{k}, \mathrm{l}$, do, dorsal view; $\mathrm{m}$, ventral and median appendages, dorsal view; $\mathrm{n}$, do, ventral view. Tanytarsus miyakoflavus, sp. nov. Male: A, head; $\mathrm{B}$, frontal tubercles; $\mathrm{C}$, wing; $\mathrm{D}$, tip of front tibia; $\mathrm{E}$, tip of hind tibia: $\mathrm{F}$, tip of middle tibia; $\mathrm{G}$, hypopygium; $\mathrm{H}$, dorsal appendage, dorsal view; $\mathrm{I}$, ventral and median appendages, dorsal view. Female: J, head; K, spermathecae; L, cercus. 
$6-9$ (7.3), pa 1 (rarely 2 or 3 ), sc 4 (rarely 5). Wing in Fig. 1-C. Anal lobe cneiform, wing with macrotrichiae more extensively distributed than in the preceding species, RR 0.36-0.51 (0.44), VR 1.09-1.20 (1.16), $\mathrm{R} / \mathrm{Cu}$ 1.02-1.07 (1.05). Tip of front tibia with a long terminal scale and a subterminal seta (Fig. 1-D), tip of middle and hind tibiae with two separated terminal scales, both bearing a long spur (Fig. 1-E, F). fLR 2.56-2.92 (2.76), mLR 0.57-0.66 (0.61), hLR 0.68-0.74 (0.72), fTR 0.350.40 (0.37), fBR 2.6-4.0 (3.0), mBR 3.9-6.2 (5.0), hBR 3.3-6.0 (4.4). Tarsi IV longer than tarsi $\mathrm{V}$ in all legs. Pulvilli absent.

Hypopygium in Fig. 1-G. Anal tergite bands separated in the middle and connected caudally with bases of lateral ridges of anal point. Ninth tergite with 2-6 (3.6) setae at base of anal point. Anal point relatively wide, parallel-sided and apically rounded, with lateral ridges and 3-5 (2.8) spine clusters situated on a longitudinal line. Dorsal appendage (Fig. 1-H) roughly oval, without distal constriction, and bearing 2-4 (2.8) inner, 2-3 (2.4) dorsal and 2-4 (3.2) lateral setae. Digitus very small and completely hidden behind dorsal appendage. Ventral appendage (Fig. 1-I) thumb-like, slightly expanded distally, bearing 8-10 (9.2) recurved setae on dorsal side and 3 caudally directed setae on ventral side of apical portion. Median appendage (Fig. 1-I) medium in length, with 3 broad lamellar setae and numerous simple setae. Gonstylus rather slender, inner margin almost straight, and widest at about middle.

Female. BL 1.65-2.33 (2.11 in average of 10$) \mathrm{mm}$, WL 1.48-1.70 (1.54) mm. Body almost entirely pale yellow; scutal stripes, postnotum and legs brownish yellow; halteres white. Head in Fig. 1-J. Frontal tubercles large, conical, 18-25 (21) $\mu \mathrm{m}$ high, 20-38 $\mu \mathrm{m}$ wide at base and $57-78(74) \mu \mathrm{m}$ apart from each other. ER $0.53-0.70 \quad(0.60)$. Antenna composed of a pedicel and 4 flagellar segments $(91,62,73,145 \mu \mathrm{m}$ in average), last segment narrowed in the middle and with a terminal seta 79-101 (92) $\mu \mathrm{m}$ long, AR 0.56-0.71 (0.64), AHR 0.53-0.70 (0.59). so 4-8 (6.5), cl 15-20 (17.1), pn 0, dm 8-16 (12.3), dl 7-13 (9.6), pa 1 (rarely 2 ), sc 4 in all. Wing wider and with more macrotrichiae than in male, RR 0.36-0.43 (0.42), VR $1.13-1.27 \quad(1.18), \quad \mathrm{R} / \mathrm{Cu} \quad 1.05-1.08$ (1.06), fLR 2.66-3.03 (2.82), mLR 0.54 0.60 (0.57), hLR 0.65-0.69 (0.68), fTR 0.34-0.39 (0.37), fBR 2.3-3.9 (2.8), mBR 2.8-4.7 (3.7), hBR 3.1-4.2 (3.6). Spermathecae (Fig. 1-K) two, both oval, 45-60 (52) $\times 38-55(43) \mu \mathrm{m}$. Cercus (Fig. 1-L) small, 53-78 (68) $\times$ 48-55 (49) $\mu \mathrm{m}$.

Type specimens. Holotype: male, No. A 64:63A. Paratypes: 11 males, A 64:64a, 66a, ChTA1-9; 10 females, A 63b, 64b, ChTB1-8.

Remarks. This species is somewhat related to $T$. gregarius Kieffer, 1909, described by various authors from Europe (Edwards, 1929, p. 410; Brundin, 1956, p. 66; Reiss and Fittkau, 1971, p. 114; Pinder, 1978, p. 156), in that body is largely yellow, anal point has lateral ridges and rather small numbers of spine clusters (6-9, mean 7.1, after Reiss and Fittkau, 1971), dorsal appendage is oval and nearly parallel to body axis, digitus is minute, and median appendage is relatively short and with both simple setae and broad lamellar setae. However, in the present species, pulvilli is completely absent (Pulvillen vorhanden in gregarius, according to Reiss and Fittkau, 1971), wing length is much smaller $(2.2-2.8 \mathrm{~mm}$ in gregarius, AR is smaller (1.26-1.46 in gregari$u s)$, and fLR is much larger (1.89-2.03 in gregarius).

Fig. 2 Tanytarsus miyakobrevis, sp. nov. and Tanytarsus sakishimanus, sp. nov.

Tanytarsus miyakobrevis, sp. nov. Female: a, head; b, spermathecae; c, cercus. Male: d, frontal tubercles; e, hypopygium; $f$, median and ventral appendages, dorsal view; $g$, dorsal appendage, dorsal view; $h$, do, ventral view. Tanytarsus sakishimanus, sp. nov. Female: A, head; B, spermathecae; C, cercus. Male: D, frontal tubercles; E, wing; F, tip of front tibia; G, tip of middle tibia; $\mathrm{H}$, tip of hind tibia; I, abdominal segments III to VI, lateral view; J, hypopygium; $\mathbf{K}$, anal point; $\mathbf{L}$, median and ventral appendages; $\mathbf{M}$, dorsal appendage, dorsal view; $\mathrm{N}$, do, ventral view. 


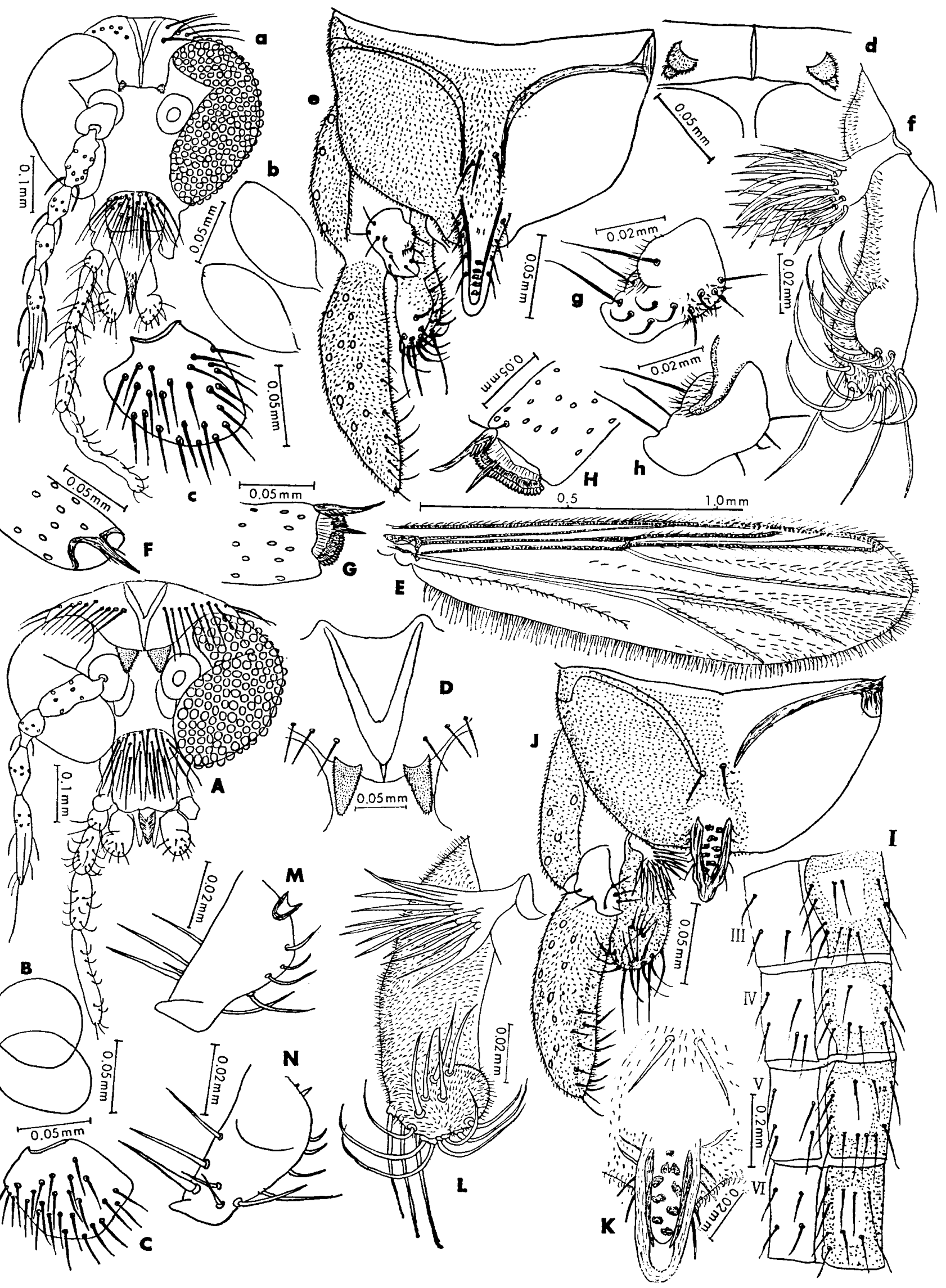

Fig. 2 


\section{Tanytarsus miyakobrevis Sasa et Hasegawa, sp. nov.}

(Fig. 2-a-h)

Many males and females emerged from a bottom sample collected on February 2, 1982, from an unpolluted stream in a plantation on Miyako Island; 10 males and 10 females among them were mounted on slides for morphological study.

Male. BL 3.05-3.73 (3.39 in average of 10) $\mathrm{mm}$, WL 1.80-2.10 (1.96) mm. Body largely yellow, with brown marks. Ground color of scutum yellow, median stripes yellowish brown and dark brown along the midline, lateral stripes brownish yellow along inner and posterior margin. Scutellum yellow, postnotum dark brown, abdominal tergites yellow, hypopygium brown, anal point and median appendages dark brown, legs brownish yellow. Frontal tubercles (Fig. 2-d) roughly conical, 21-43 (28) $\mu \mathrm{m}$ high, 18-28 (21) $\mu \mathrm{m}$ wide at base, and 42-95 (71) $\mu \mathrm{m}$ apart from each other. Eyes with a narrow dorsomedial projection, ER 0.47-0.56 (0.52). Antenna with 13 flagellar segments, AR 1.25-1.38 (1.33), AHR 0.46-0.53 (0.50). so 8-14 (10.6), cl 16-21 (18.0), pn 0 , dm 12-18 (14.9), dl 7-13 (10.1), pa 1, sc 6-8 (7.0). Wing bluish, coarsely granular, with macrotrichiae on almost entire wing membrane and veins (except $\mathrm{R} 2+3$ and subcosta, which are bare). Squama bare, anal lobe cneiform, anal vein ending before $\mathrm{fCu}$. RR 0.36-0.50 (0.44)， VR 1.15-1.22 (1.19), $\mathrm{R} / \mathrm{Cu}$ 1.03-1.11 (1.06). fLR 2.47-3.13 (2.89), mLR 0.62-0.68 (0.65), hLR 0.680.73 (0.71), fTR 0.38-0.41 (0.39), fBR 3.13.7 (3.3), mBR 4.0-5.9 (4.7), hBR 4.1-7.5 (4.9). Terminal scale of front tibia with a narrow and sharply pointed process, terminal combs of middle and hind tibiae separated, both with a long spur. Pulvilli absent.

Hypopygium in Fig. 2-e. Bands on ninth tergite widely separated in the middle. Ninth tergite with 2-4 (3.6) setae at base of anal point. Anal point slightly tapering towards rounded apex, with lateral ridges and 4-10 (7.4) lateral setae, and 3-8 (6.3) spine clusters in a single row. Dorsal appendage roughly elongate oval but slightly constricted near apex, with 3-4 (3.1) inner and 7-10
(8.4) dorsal setae, the long axis directed slightly inwards against the body axis, with microtrichiae on inner side (Fig. 2-g, h) . Digitus small and completely hidden behind dorsal appendage (Fig. 2-h). Ventral appendage finger-like, slightly expanded apically, with 13-20 (18.0) recurved setae on apical half of dorsal side, and 3 straight setae on ventral side near apex. Median appendage (2-f) short, directed inwards, with numerous short setae arranged in a thick tuft (Fig. 2-f).

Female. BL 2.58-3.23 (2.83 in average of 10$) \mathrm{mm}$, WL 1.95-2.21 (2.04) mm. Body largely yellow, both median and lateral scutal stripes brown along inner margin as in male, abdomen yellow, legs brownish yellow. Head in Fig. 2-a ER 0.35-0.48 (0.41), frontal tubercles conical, 13-20 (15) $\mu \mathrm{m}$ high, 10 23 (17) $\mu \mathrm{m}$ wide at base, and 47-81 (70) $\mu \mathrm{m}$ apart from each other. Antenna composed of a pedicel and 4 flagellar segments (113, 79, 93, $184 \mu \mathrm{m}$ in average), last segment with a subterminal seta of 115-148 (132) $\mu \mathrm{m}$ long, AR 0.60-0.72 (0.65), AHR $0.54-0.68(0.60)$. so $7-12(9.3)$, cl 18-23 (20.1), pn 0, dm 14-22 (17.6), dl 13-23 (18.1), pa $1: 1$ in all, sc 6-10 (8.1). Wing bluish and granular, with numerous macrotrichiae, as in male. RR 0.32-0.45 (0.39), VR 1.13-1.26 (1.18), fLR 2.69-2.95 (2.81), mLR $0.62-0.69$ (0.64), hLR $0.68-0.72$ (0.70), fTR 0.36-0.40 (0.39), fBR 2.5-3.5 (2.9), mBR 2.9-5.5 (3.9), hBR 2.8-5.2 (3.7). Spermathecae (Fig. 2-b) 44-68 (55) $\times 61-95(74) \mu \mathrm{m}$, cercus 80-105 (90) × 6578 (71) $\mu \mathrm{m}$ wide, both larger and relatively longer than in female of the preceding species.

Type specimens. Holotype: a male, No. A 64:65a. Paratypes: 9 males, ChTC1-9, and 10 females, A 64:65b, ChTD1-9. All collected on Miyako Island on February 2, 1982.

Remarks. This species again related to T. gregarius Kieffer, 1909, known from Europe, in that anal tergite bands are separated, anal point has lateral ridges and small numbers of spine clusters, dorsal appendage is roughly oval and digitus is very small, and median appendage is rather short and directed inwards. However, it differs from gregarius in that anal tergite bands are ex- 
tending to bases of lateral ridges of anal point, long axis of dorsal appendage is conspicuously oblique to body axis, dorsal appendage is slightly constricted near apex and with microtrichiae on both inner and lateral margins, median appendage bears more numerous setae, and pulvilli are absent. It is also related to the former species collected on the same island, $T$. miyakoflavus, but differs from it in the structure of median appendage (with numerous simple setae in the present species, with broad lamellae setae in the former), in the shape and presence or absence of microtrichiae on dorsal appendage, and in the distribution of recurved setae on ventral appendage (arising over the distal half in the present species, restricted to only the apical portion in the former).

\section{Tanytarsus sakishimanus Sasa et Hasegawa, sp. nov.}

(Fig. 2-A-N)

Five males and 2 females emerged from bottom sand of a water filtration pond of Ishigaki City, Ishigaki Island, collected on February 1, 1982 (Nos. A 64:68a, b, 69a, b, ChTE1-3). A male and a female emerged also from bottom sand of a pond on Miyako Island, collected on February 2, 1982 (Nos. A 64:67a, b). Four males emerged from a bottom sample of a taro paddy in Ohyama, Ginowan-shi, Okinawa Island, on April 10, 1983 (ChTE4-7). A male was collected at Itoman-shi, Okinawa Island, on August 11, 1982 (ChTE8).

Male. BL 2.88-3.65 (3.24 in average of 11) $\mathrm{mm}$, WL 1.55-1.95 (1.77) $\mathrm{mm}$. Ground color of scutum nearly white, scutal stripes dark brown, scutellum white. postnotum dark brown; halteres white; femora largely yellow, brown apically; tibiae and tarsi yellowish brown. Abdominal tergites II to VI each with a pair of large pale areas surrounded in the middle by longitudinal dark brown band, and dark brown areas along caudal as well as oral margin of each segment (Fig. 2-I) ; tergites VII and VIII brown, hypopygium largely brown but anal point, dorsal appendage and bands of ninth tergite dark brown. Frontal tubercles (Fig. 2-D) well developed, 38-65 (49) $\mu \mathrm{m}$ high, 23-30 (28) $\mu \mathrm{m}$ wide, and about 65-73 (67) $\mu \mathrm{m}$ apart from each other. Eyes bare, ER 0.46-0.73 (0.66). Antenna with 13 flagellar segments, AR 1.09-1.31 (1.18), AHR 0.47$0.55(0.50)$. so 8-14 (10.6), cl 16-22 (18.6), pn 0 , dm 12-16 (13.6), dl 7-11 (8.4), pa 1 (rarely 2), sc 4-7 (5.2). Wing membrane bluish, finely granular. Wing venation in Fig. 2-E. Squama bare, anal lobe obtuse, with macrotrichiae rather sparsely and restricted mainly to distal half, on veins $R$, $\mathrm{R} 1, \mathrm{R} 4+5, \mathrm{M}, \mathrm{Cu} 1, \mathrm{Cu} 2$ and $\mathrm{An}$, as well as in the cells between $\mathrm{R} 4+5$ and $\mathrm{M}, \mathrm{M}$ and $\mathrm{Cu} 1, \mathrm{Cu} 1$ and $\mathrm{Cu} 2$, and behind An. Costa ending at tip of $\mathrm{R} 4+5$. RR $0.33-0.43$ (0.39), VR 1.07-1.16 (1.12), R/Cu 1.02$1.11(1.06)$. Anal vein ending proximal to fCu. fLR 2.29-2.53 (2.40), mLR 0.62-0.67 (0.64), hLR 0.67-0.75 (0.72), fTR $0.32-$ 0.39 (0.36), fBR 3.1-4.3 (3.4), mBR 3.8-7.2 (5.2), hBR 3.7-6.9 (5.3). Terminal scale of front tibia with a long and narrow process (Fig. 2-F). Terminal combs of middle and hind tibiae separated, one wide and the other narrow, both with a long spur (Fig. 2-G, H). Pulvilli absent. Both abdominal tergites and sternites with reduced numbers of setae (Fig. 2-I).

Hypopygium in Fig. 2-J. Bands of ninth tergite widely separated in the middle. Ninth tergite with 1-3 (2.1) setae at about the tips of bands or anterior to the base of anal point. Anal point (Fig. 2-K) with darkly pigmented lateral ridges, several short lateral setae, and 3-10 (7.9) spine clusters in irregular rows. Dorsal appendage (Fig. 2-M, N) with nearly straight inner margin and strongly convex lateral margin, abruptly narrowed near apex, and a triangular apical process, bearing 3-4 (3.1) inner, 2-4 (2.8) dorsal, and 2-6 (4.9) lateral setae. Digitus (Fig. 2-N) very small, situated at the base of ventral side of dorsal appendage, and almost completely hidden behind it. Ventral appendage finger-like, slightly expanded apically, with 11-17 (14.0) recurved setae on dorsal side and 1-4 (2.8, usually 3 ) caudally directed straight setae on the ventral side of apical portion (Fig. 2-L). Median appendage composed of a short stem. and numerous stout and simple setae directed inwards or caudally (Fig. 2-L). Gonostylus with almost straight inner margin and smoothly convex lateral margin, bearing two rows of short setae along inner margin, bear- 
ing two rows of short setae along inner margin.

Female. BL 2.34, 2.42, $2.58 \mathrm{~mm}$, WL $1.58,1.66,1.78 \mathrm{~mm}$. Body coloration as in male but generally paler; ground color of scutum yellow, stripes brown, scutellum yellow, postnotum brown, abdominal tergites largely yellow and with brown patches, hypopygium brown, leg segments yellowish brown. Head in Fig. 2-A. Frontal tubercles prominent, roughly conical. Antenna with 5 flagellar segments, AR 0.52, 0.59, 0.63, AHR $0.43,0.43,0.47, \mathrm{cl} 18,24,32$, so $7: 7$, $8: 8,9: 9$, pn 0 , dm $14,15,18$, dl $8: 8,9: 11$, $12: 12$, pa $1: 1$ in all, sc $7,8,10$. Macrotrichiae on wing membrane more numerous than in male. RR $0.34,0.37,0.39$, VR 1.17 , $1.21,1.26, \mathrm{R} / \mathrm{Cu} 1.10,1.12,1.12$, sq 0 , fLR $2.20,2.30,2.50$, mLR $0.59,0.65,0.65$, hLR $0.67,0.76$, fTR $0.31,0.36,0.41$, fBR 2.5, 2.6, 2.9, mBR 2.7, 3.0, hBR 3.0, 3.3. Pulvilli absent. Spermathecae in Fig. 2-B, cercus in Fig. 2-C.

Type specimens. Holotype: male, No. A 65:12a, collected on Ishigaki. Paratypes: 10 males and 3 females, collected on Ishigaki, Miyako and Okinawa Islands.

Remarks. This species is somewhat related to Tanytarsus oyamai Sasa, 1979, which is one of the most common species breeding in rice paddies and ponds in the mainland of Japan, especially in the structure of wing and hypopygium. However, the present species can be distinguished from it by the following points.

1) Abdominal tergites II to VI have a pair of large pale areas in the middly, as shown in Fig. 2-I, while they are almost uniformly dark brown in T. oyamai. 2) Anal point has 8-10 spine clusters distributed irregularly in multiple rows, while they are only 3-6 and distributed in a single longitudinal line in T. oyamai. 3) Dorsal appendage is roughly oval and with an apical hook, while that of $T$. oyamai is abruptly constricted at about $1 / 3$, and without apical hook. 4) Digitus is much smaller than that of $T$. oyamai. 5) Median appendage has more numerous branches than in $T$. oyamai. 6) In $T$. oyamai, AR is $0.86-1.12$, $\mathrm{fLR}$ is 1.60-1.79, and both smaller than 1.09-1.31 or 2.29-2.53 of the present species. The measurement data and morphological char- acteristics of $T$. oyamai were shown in the original description by Sasa (1979, p. 3, Fig. 5).

\section{Eukiefferiella yaraensis Sasa et Hasegawa, sp. nov.}

(Fig. 3-a-h)

Two males were collected on December 11,1981 , with insect net on the shore of the Hija River under Yara Bridge, Kadena-cho, Okinawa, where the water was highly eutrophicated.

Male. BL 2.04, $2.10 \mathrm{~mm}$, WL 1.27, 1.34 $\mathrm{mm}$. Ground color of scutum yellow, stripes dark brown, scutellum yellowish brown, postnotum dark brown, abdominal tergites yellowish brown; halters yellow; leg segments yellowish brown. Head in Fig. 3-a. Eyes bare, inner margin slightly concave, without dorsomedial projection, ER 1.37, 1.55 Antenna with 13 flagellar segments, AR 0.78, 0.88, AHR 0.46, 0.51. Supraorbital setae absent in the median portion, 3 or 4 in the lateral portions. $\mathrm{cl} \mathrm{6,8.}$

Antepronotum (Fig. 3-b) narrowly separated in the middle, with 2 lateral setae on each side. Scutum and scutellum in Fig. 3-c, $\operatorname{dm} 0$, dl $8: 9,8: 8$, pa $3: 3,4: 3$, scutellar setae 6 in both specimens. Wing in Fig. 3-d. $\mathrm{R} 2+3$ almost fused with $\mathrm{R} 4+5, \mathrm{RR} 0.87$, 0.90 . Costa extending beyond end of $R 4+5$, which is much proximal to end of $\mathrm{Cu} 1$, $\mathrm{R} / \mathrm{Cu} 0.84,0.90$. fCu much beyond $\mathrm{r}-\mathrm{m}$, VR 1.32, 1.35. Gu2 almost straight. Anal vein extending much beyond $\mathrm{fCu}$.

Front tibia with a long terminal spur (45 $\mu \mathrm{m}$, Fig. 3-e ). Middle tibia with two short terminal spurs $(12,20 \mu \mathrm{m}$, Fig. 3-f $)$. Hind tibia with a long terminal spur $(45 \mu \mathrm{m})$, a short terminal spur $(17 \mu \mathrm{m})$, and a terminal comb composed of 13 free spurs $(20-41 \mu \mathrm{m}$, Fig. 3-g). All tarsi without terminal spurs. In the front legs, tarsus IV $(58 \mu \mathrm{m})$ is longer than tarsus $V$, while in the middle and hind legs, tarsi IV $(58,79 \mu \mathrm{m})$ are shorter than tarsi $\mathrm{V}(68,76 \mu \mathrm{m})$. Pulvilli absent.

Hypopygium in Fig. 3-h. Ninth tergite with neither anal point nor long setae, posterior margin rounded. Inner lobe of gonocoxite nearly as long as wide, with rounded margin. Gonostylus simple, almost parallelsided, with a terminal spur but without sub- 
terminal tooth.

Type specimens. Holotype: male, No. A 65:77a. Paratype: male No. A 65:78a. Type loc. Kadena-cho, Okinawa.

Remarks. This species is classified as a member of the genus Eukiefferiella, because the structure of hypopygium, wing veins and other body parts are similar to those of certain species of this complicated genus. Among the species of this genus known from Europe, it is most closely related to E. claripennis (Lundbeck) redescribed and illustrated by Pinder (1978) in that anal point is absent, eyes are bare, gonostylus is not expanded basally, and costa is ending much proximal to tip of $\mathrm{Cu} 1$, but the shape and structure of inner lobe of gonocoxite and gonostylus are quite different from each other. Among the species of this genus recorded from Japan, it is most closely related to E. yasunoi Sasa, 1979, in the above stated morphological characters, but it again differs from E. yasunoi in AR (0.44-0.52 in yasunoi), absence of $\mathrm{dm}$ ( $\mathrm{dm}$ present in yasunoi), and in the shape of inner lobe of gonocoxite (rouded in the present species, elongate and quadrangulate in yasunoi). E. yasunoi was collected from clean mountain streams on Mount Tsukuba (Ibaraki), while E. yaraensis was found at the side of a highly polluted stream on Okinawa Island.

\section{Rheocricotopus chalybeatus (Edwards, 1929)}

(Fig. 3-A-Q)

Altogether 13 males and 14 females were collected with insect net on the bank of eutrophicated ponds and streams on the three large islands surveyed, i.e. 2 males and 2 females on Ishigaki (No. A 65:91-93), 3 males and 3 females on Miyako (A 65:34, 99, 100), and 8 males and 9 females on Okinawa (A 65:79, 85-89, 91, 95-98).

Male. BL $2.32-2.82(2.56 \pm 0.16) \mathrm{mm}$ in

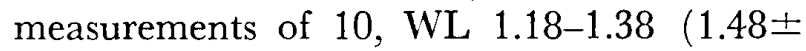
$0.11) \mathrm{mm}$. Body largely black; ground color of scutum dark brown; scutal stripes, scutellum, postnotum and abdominal tergites black, sternites brown; halteres dark brown; legs dark brown. Eyes highly pubescent, without dorsomedial projection and widely apart from each other, ER 1.28-1.73 (1.54). An- tenna with 13 flagellar segments. AR 1.181.38 (1.28), AHR 0.46-0.62 (0.52), supraorbital setae composed of an inner pair, and 3-5 lateral pairs, cl 14-19 (15.2). Antepronotum with double lobes in the middle, and with 2-6 (4.2) lateral setae (Fig. 3-F). Scutum with a pair of large humeral pits $(\mathrm{hm}), \mathrm{dm} 0, \mathrm{dl} 10-16(12.9)$, pa 3 or 4 (3.4), sc 10 or 12 (Fig. 3-K). Wing bare. slightly brownish, venation in Fig. 3-E. Costa not extending beyond end of $\mathrm{R} 4+\overline{\mathrm{j}}$. $\mathrm{R} 2+3$ ending about midway between ends of R1 and R4+5, RR 0.48-0.55 (0.51). $\mathrm{fCu}$ slightly beyond $\mathrm{r}-\mathrm{m}, \mathrm{VR}$ 1.06-1.16 (1.10). R4+5 ending slightly beyond end of $\mathrm{Cu} 1, \mathrm{R} / \mathrm{Cu} 1.02-1.08$ (1.05). Cu2 slightly curved near the tip. Anal vein extending much beyond fCu. Squama with 6-10 (8.2) fringe hairs. Anal lobe rather conspicuously produced. Front tibia with a long terminal spur $(50 \mu \mathrm{m}$; Fig. 3-G). Middle tibia with two short terminal spurs $(16,17 \mu \mathrm{m}$; Fig. $3-\mathrm{H})$. Hind tibia with a long terminal spur $(45 \mu \mathrm{m})$, a short terminal spur $(18 \mu \mathrm{m})$, and a terminal comb composed of 12 or 13 free spurs $(30-58 \mu \mathrm{m}$; Fig. 3-I, J). fLR 0.64-0.67 (0.66), mLR 0.54-0.58 (0.56), hLR $0.57-0.61 \quad(0.59), \quad$ fTR $0.14-0.15$ (0.142), fBR 1.8-3.5 (2.2), mBR 2.0-3.7 (3.0), hBR 2.4-4.1 (3.4). All legs with a pair of large pulvilli, claws and empodium.

Abdominal tergites with rather reduced numbers of setae, arranged roughly into the lateral and the middle groups. Hypopygium in Fig. 3-L. Anal point the Orthocladius type, i.e. widest at base and tapering towards sharply pointed apex, with lateral setae, and with microtrichiae on basal $2 / 3$, distal $1 / 3$ bare. Inner lobes of gonocoxite doublelayered, the dorsal lobe roughly rectangular, without microtrichiae and with several short setae on inner margin, the ventral lobe wider and obtuse, thickly covered with microtrichiae (Fig. 3-M, N). Gonostylus apically expanded and sharply curved inwards, with a strong apical spur, and a conspicuous subapical swelling (Fig. 3-P, Q).

Female. BL 1.94-2.22 (2.07 in average of 8$) \mathrm{mm}$, WL $1.22-1.57$ (1.45) mm. Body largely black as in male; ground color of scutum dark brown, stripes, scutellum and postnotum black, abdominal tergites dark brown, sternites brown, halteres dark brown, 


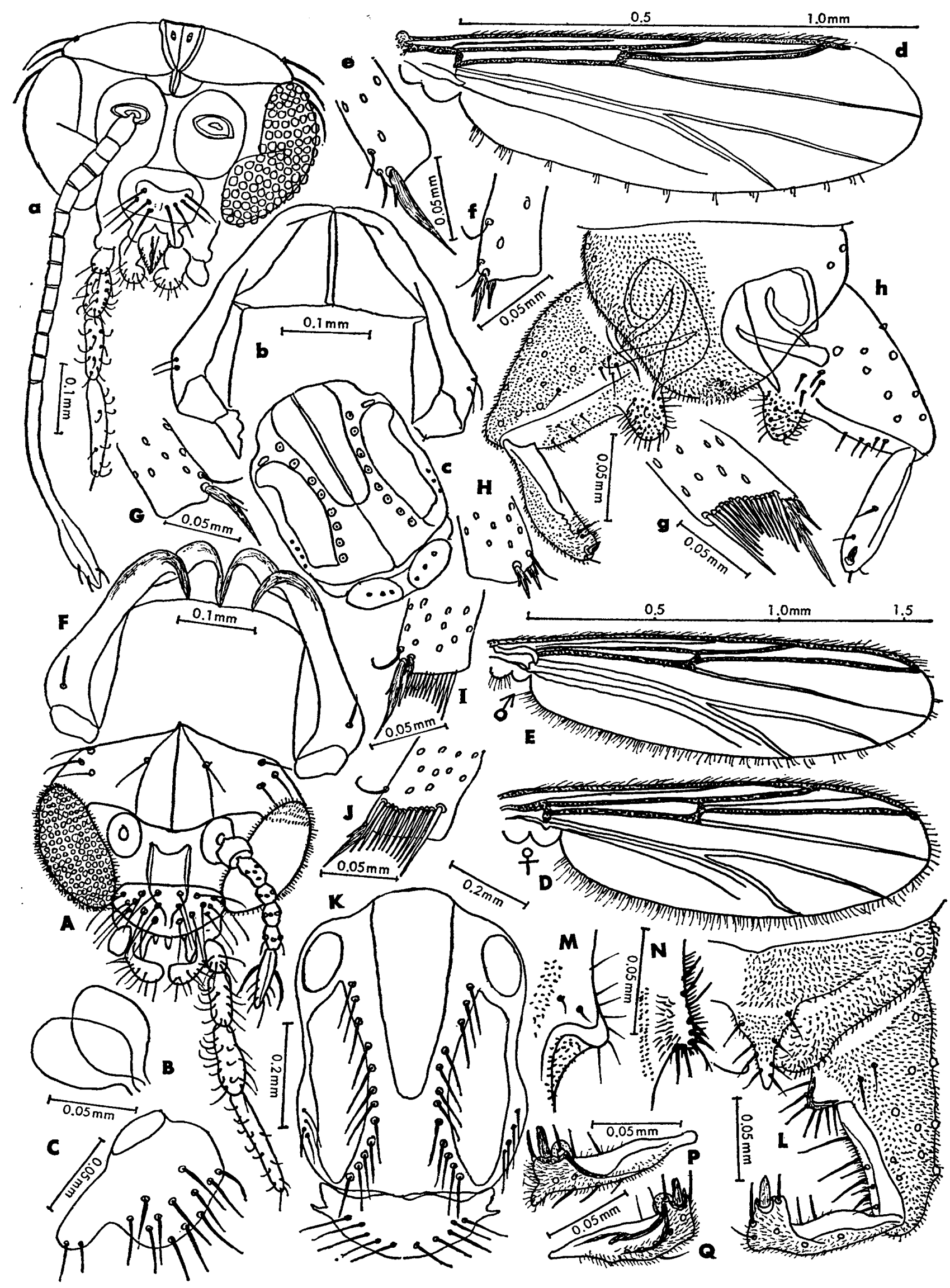

Fig. 3 
leg segments dark brown. Head in Fig. 3-A. Eyes oval and without dorsomedial projection, ER 1.29-1.53 (1.39), highly pubescent. Antenna composed of a pedicel and 5 flagellar segments, AR 0.52-0.60 (0.55), AHR 0.31-0.42 (0.38). Supraorbital setae composed of an inner pair, and 3, 4 or 5 lateral pairs, cl 16-20 (17.6). Antepronotum showing peculiar structure, as in male, with 2-5 (3.4) lateral setae. Scutum with a pair of large humeral pits as in male. $\mathrm{dm} 0, \mathrm{dl} 12$ 22 (17.1), pa 3-6 (usually 3 or 4, mean 3.4 ), sc 10-16 (12.6). Wing membrane bare, brownish (darker than in male wing), smooth, veins thicker than in male. Wing venation in Fig. 3-D. Costa slightly extending beyond end of $\mathrm{R} 4+5 . \mathrm{R} 2+3$ ending about midway between end of $\mathrm{R} 1$ and $\mathrm{R} 4+5$, RR 0.46-0.53 (0.50). VR 1.04-1.21 (1.11). $\mathrm{R} 4+5$ ending slightly beyond end of $\mathrm{Cu} 1$, $\mathrm{R} / \mathrm{Cu}$ 1.03-1.08 (1.05). Anal vein extending much beyond fCu. Squama with 8-10 (8.5) fringe hairs. Anal lobe obtuse. Spermathecae (Fig. 3-B) two, both oval and colorless. Cercus (Fig. 3-C) with a conspicuous ventral projection.

Remarks. This species is a typical member of genus Rheocricotopus Thienemann et Harnisch, 1932, since eyes are pubescent and without dorsomedial projection, hypopygium has a large anal point bearing lateral setae, scutum has a pair of large humeral pits, wings are bare, squama are fringed, and gonostylus is simple. The present species is identified as $R$. chalybeatus (Edwards), because gonostylus is abruptly curved upwards at tip (a characteristic of this species). The structure of hypopygium, the presence of large humeral pits and measurement data fit to the description of this species by various authors from Europe. $R$. chalybeatus was recorded also by Tokunaga (1938, p. 319) from Kyoto and Osaka, and by Sasa and Kawai (1987a, p. 43) from Lake Biwa (Shiga).

\section{Metriocnemus ryutanus Sasa et Hasegawa, sp. nov.}

(Fig. 4-a-h)

A male (holotype) was collected with insect net on the shore of Lake Ryutan, Shuri, Okinawa Island, on December 7, 1981 (No. A 65:31).

Male. BL $2.26 \mathrm{~mm}$, WL $1.44 \mathrm{~mm}$. Ground color of scutum yellow, scutal stripes reddish brown, scutellum yellowish brown, postnotum dark brown, abdominal tergites brown; leg segments brownish yellow; halteres yellow. Head in Fig. 4-a. Eyes bare, each with a long dorsomedial projection, ER 0.58 (very small as a member of Orthocladiinae). Antenna with 13 flagellar segments, AR 0.94, AHR 0.49, last segment not expanded apically, without apical seta. Palp 4 segmented as usual. Scutum and scutellum in Fig. 4-b; so $13: 13, \mathrm{cl} 12, \mathrm{dm} 20$, dl $27: 27$, pa $8: 11$, sc 10 , all relatively large in the numbers. Wing (Fig. 4-c) with numerous macrotrichiae both on veins and membrane. $\mathrm{R} 4+5$ ending much proximal to end of $\mathrm{Cu} 1$ and to the tip of wing, $\mathrm{R} / \mathrm{Cu}$ ratio 0.84 . Costa extending much beyond end of $\mathrm{R} 4+5$. $\mathrm{R} 2+$ 3 ending about midway between ends of $R 1$ and $\mathrm{R} 4+5$, RR 0.56. fCu beyond $\mathrm{r}-\mathrm{m}$, VR 1.17. $\mathrm{Cu} 2$ slightly curved. Anal vein ending under fCu. Squama with 6 fringe hairs, anal lobe obtuse. Leg ratios relatively high, fLR 0.80 , mLR 0.56 , hLR 0.70 , fTR 0.13 . Tarsi with long beards, fBR 3.9, mBR 5.8, hBR 6.0. All tarsi cylindrical, pulvilli absent. Front tibia with a long terminal spur (62 $\mu \mathrm{m}$; Fig. 4-d). Middle tibia with two short terminal spurs $(20,22 \mu \mathrm{m}$; Fig. 4-e). Hind tibia with a long terminal spur $(53 \mu \mathrm{m})$, a short terminal spur $(25 \mu \mathrm{m})$, and a terminal comb composed of 8 free spurs 30-48 $\mu \mathrm{m}$ long (Fig. 4-f). Ninth tergite without long setae.

Hypopygium in Fig. 4-g, h. Anal point

Fig. 3 Eukiefferiella yaraensis, sp. nov, and Rheocricotopus chalybeatus (Edwards).

Eukiefferiella yaraensis, sp. nov. Male: a, head; b, antepronotum; c, scutum and scutellum; $\mathrm{d}$, wing; e, tip of front tibia; $\mathrm{f}$, tip of middle tibia; $\mathrm{g}$, tip of hind tibia; h, hypopygium. Rheocricotopus chalybeatus (Edwards) Female: A, head; B, spermathecae; C, cercus; $D$, wing. Male: $E$, wing; $F$, antepronotum; $G$, tip of front tibia; $H$, tip of middle tibia; I, J, tip of hind tibia; K, scutum and scutellum; L, hypopygium; M, inner lobes of gonocoxite, dorsal view; $N$, do, ventral view; $P, Q$, gonostylus. 


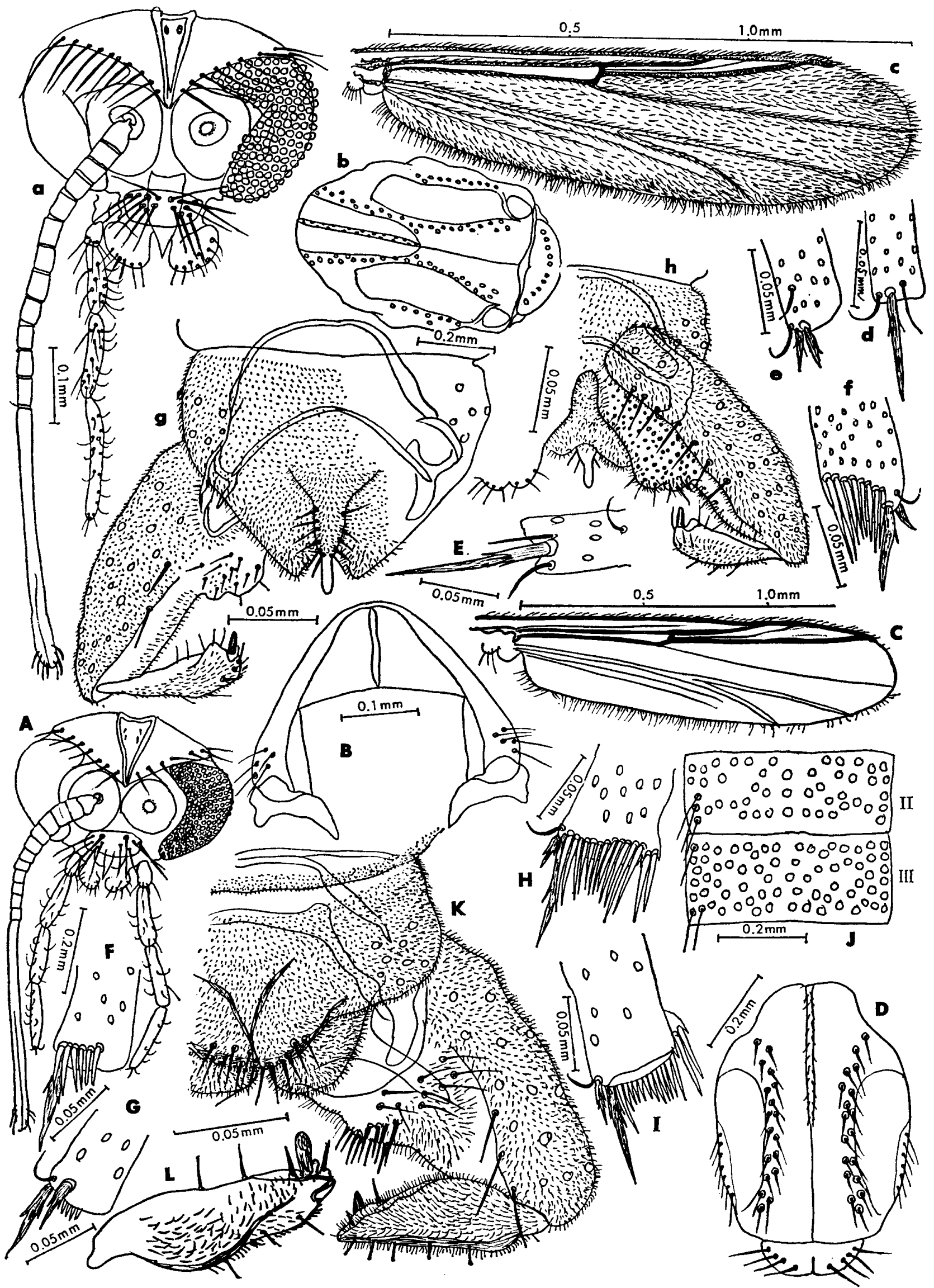

Fig. 4 
robust, widest at base, thickly covered with microtrichiae and with lateral setae on basal $3 / 4$, distal $1 / 4$ bare and rounded apically. Inner lobe of gonocoxite single, low, broad and obtuse. Gonostylus simple, widest at about distal 1/3, lateral margin convex and inner margin almost straight, with a strong apical spur, and a small subapical swelling.

Remarks. This species belongs to the genus Metriocnemus van der Wulp, 1874, since it has wings with macrotrichiae on almost entire surface, simple gonostylus, bare eyes, almost straight $\mathrm{Cu} 2$, a large anal point, and costa extending much beyond end of $\mathrm{R} 4+5$. This genus is relatively rich in species. Goetghebuer (1940) recorded 12 species from Europe, and Pinder (1978) gave 10 species in his key to British Chironomidae. Among them, the present species seems to be most closely related to $M$. cavicola Kieffer, 1921 , since wing is almost entirely covered with macrotrichiae, gonocoxite has a large basal lobe, and AR is about 1.0. However, the structure of male hypopygium is essentially different between these species, i.e. in $M$. cavicola anal point has no lateral setae, inner lobe of gonocoxite is much larger, and gonostylus has no subapical tooth.

Three species of genus Metriocnemus have been recorded from Japan, including the present new species. Their males can be differentiated from each other by the following key.

1. AR 2.5-3.0; gonocoxite without inner lobe; thorax black ......... picipes (Meigen, 1818) of Tokunaga, 1940

- AR about 1.0 ; gonocoxite with a conspicuous inner lobe ........... 2

2. Scutellum with $32-38$ setae distributed in multiple rows, prealar setae 20-36 on each side; anal point without lateral setae, and covered entirely with microtrichiae; ninth tergite with 22-35 long setae; tarsi I and II of middle legs and tarsi $I$ of hind legs with two terminal spurs; body almost entirely black .... ............. tamaokui Sasa 1983

-. Scutellum with about 10 setae in a transverse row; prealar setae 8-12; anal point with lateral setae, and with microtrichiae restricted to basal $2 / 3$; ninth tergite without long setae; tarsi without apical spurs; body largely yellow, with brown marks ...... ryutanus sp. nov.

\section{Okinawayusurika Sasa and Hasegawa, gen. nov.}

Chironomidae: Orthocladiinae: Metriocnemini. Male: Eyes bare, inner margin concave. Antenna with 13 flagellar segments, last segment slightly swollen apically, without terminal seta. Palp 4 segmented. Antepronotum completely united in the middle, with lateral setae but without dorsal setae. $\mathrm{dm}$ minute and restricted to the anterior half of scutum. dl arising from large pale pits. Wing membrane bare and coarsely granular: squama with a few fringe hairs; costa not extending beyond end of $\mathrm{R} 4+5$; $\mathrm{fCu}$ beyond $\mathrm{r}-\mathrm{m} ; \mathrm{Cu} 1$ ending proximal to end of $\mathrm{R} 4+5 ; \mathrm{Cu} 2$ almost straight; anal vein faint, extending beyond fCu. Leg segments long and slender; front tibia with a long and slender terminal spur; middle and hind tibiae each with a long terminal spur, a short terminal spur, and a terminal comb composed of free spinules; tarsus IV longer than tarsus $\mathrm{V}$ in all legs; pulvilli absent. Hypopygium without anal point; inner lobe of gonocoxite broad and low, and bearing short and strong setae; gonostylus simple. widest at about middle, with a strong terminal spur.

Type species. Okinawayusurika otsurui Sasa et Hasegawa, sp. nov., monotypic.

This generic name is originated from "Okinawa" (name of the prefecture), and "Yusurika" (Japanese common name for chironomid midges). The gender of this

Fig. 4 Metriocnemus ryutanus, sp. nov. and Okinawayusurika otsurui, gen. nov., sp. nov. Metriocnemus ryutanus, sp. nor. Male: $a$, head; b, scutum and scutellum, showing distribution of setae; c, wing: $d$, tip of front tibia; e, tip of middle tibia; $f$, tip of hind tibia; $\mathrm{g}$, hypopygium, dorsal view; h, do, ventral view. Okinawayusurika otsurui, gen. nov., sp. nov. Male: A, head; B, antepronotum; C, wing; D, scutum and scutellum; E, tip of front tibia; F, G, tip of middle tibia; H, I, tip of hind tibia; J, abdominal tergites II and III, showing distribution of setae: $\mathbf{K}$, hypopygium; $L$, gonostylus. 
generic name is feminine.

\section{Okinawayusurika otsurui Sasa et Hasegawa, gen. et sp. nov.}

(Fig. 4-A-L)

A male (holotype) was collected on February 3, 1982, on the shore of a small eutrophicated pool of the primary school on Ikema Island, Miyako (No. A 65:16).

Male. BL $2.36 \mathrm{~mm}$, WL $1.52 \mathrm{~mm}$. Ground color of scutum yellow, stripes dark brown, scutellum yellowish brown, postnotum dark brown, abdominal tergites brown, sterniates yellowish brown, halteres yellow, leg segments brown. Head in Fig. 4-A. Eyes bare, inner margin strongly concave, ER 0.80 . Antenna with 13 flagellar segments, AR 1.31, AHR 0.59, last segment only slightly swollen apically, with several short sensory setae in the apical portion but without terminal seta such as seen in some Smittia species. Palp 4 segmented. Supraorbital setae 8 on both sides. Antepronotum (Fig. 4-B) narrow but completely united in the middle, with 5 lateral setae. Scutum and scutellum in Fig. 4-D. $\mathrm{dm} 22$ in two rows, all minute and starting from near anterior margin. dl 18:18, all arising from large pale pits, prealar setae $6: 7$, scutellar setae 7 .

Wing in Fig. 4-C. Wing membrane bare, coarsely granular such as in Limnophyes species, slightly bluish under transmitted light. Squama with 3:3 fringe hairs. Costa not extending beyond end of $R 4+5 . R 2+3$ ending closer to end of $R 1, R R \quad 0.36$. fGu beyond $r-m, V R$ 1.22. Cu1 ending proximal to end of $\mathrm{R} 4+5$. Cu2 almost straight. Anal vein rather faint, extending beyond $\mathrm{fCu}$. Leg segments relatively long and slender, fLR 0.61, mLR 0.52, hLR 0.60, fTR 0.13. Tip of front tibia with a very long and slender terminal spur $(83 \mu \mathrm{m}$, Fig. 4-E). Middle tibia with a long terminal spur ( 52 $\mu \mathrm{m})$, a short terminal spur $(30 \mu \mathrm{m})$, and a terminal comb composed of 6 free spurs (24-30 $\mu \mathrm{m}$, Fig. 4-F, G). Hind tibia with a long terminal spur $(62 \mu \mathrm{m})$, a short terminal spur $(30 \mu \mathrm{m})$, and a terminal comb composed of 15 free spurs $(28-46 \mu \mathrm{m}$, Fig. 4-H, I). All tarsi without terminal spurs. Tarsus I with a relatively long beards, fBR 4.0. Tarsus IV much longer than tarsus $\mathrm{V}$ in all legs. Claws well developed, empodium rather small, pulvilli absent.

Abdominal tergites with relatively large numbers of setae, which are almost evenly distributed (Fig. 4-J). Hypopygium in Fig. 4-K. Anal point absent, but ninth tergite with a broad and rounded lobe with darkly pigmented posterior margin and with a wedge-shaped pale area in the middle and 10 strong setae on posterior margin. Inner lobe of gonocoxite broad and low, bearing 10 spine-like setae with strong bases. In addition, gonocoxite has 10 long and slender setae in the area lateral to the inner lobe. Gonostylus (Fig. 4-L) widest at about middle, with a strong terminal spur $18 \mu \mathrm{m}$ long and $6 \mu \mathrm{m}$ wide.

Remarks. Okinawayusurika is somewhat related to certain species of the genus Limnophyes Eaton in that wing membrane is coarsely granular, squama has very small numbers of fringe hairs, $\mathrm{Cu} 2$ is almost straight, and anal point is absent. However, the present new genus is essentially different from Limnophyes and all the other genera of the subfamily Orthocladiinae in that the middle tibia has a terminal comb, such as seen in the tip of hind tibia of the most other species of this subfamily. It is also characteristic in having a rudimentary inner lobe on gonocoxite.

This species name is dedicated to Professor Masamitsu Otsuru, former Dean of the School of Medicine and also Chairman of the Department of Parasitology, University of the Ryukyus.

\section{Pseudosmittia ikemaensis Sasa et Hasegawa, sp. nov.}

(Fig. 5-a-p)

Adults of this species were found swarming on the bank of a small eutrophicated pool in the primary school of Ikema Island, Miyako, on February 3, 1982; 18 males and 3 females were studied as slide specimens.

Male. BL 2.10-2.18 (2.14 in average of 10) $\mathrm{mm}$, WL 1.08-1.22 (1.14) $\mathrm{mm}$. Scutum almost uniformly black, scutellum dark brown, postnotum black, abdominal tergites dark brown, anal point black, legs dark brown, halteres brown. Head in Fig. 5-e. Eyes bare, reniform, without dorsomedial 


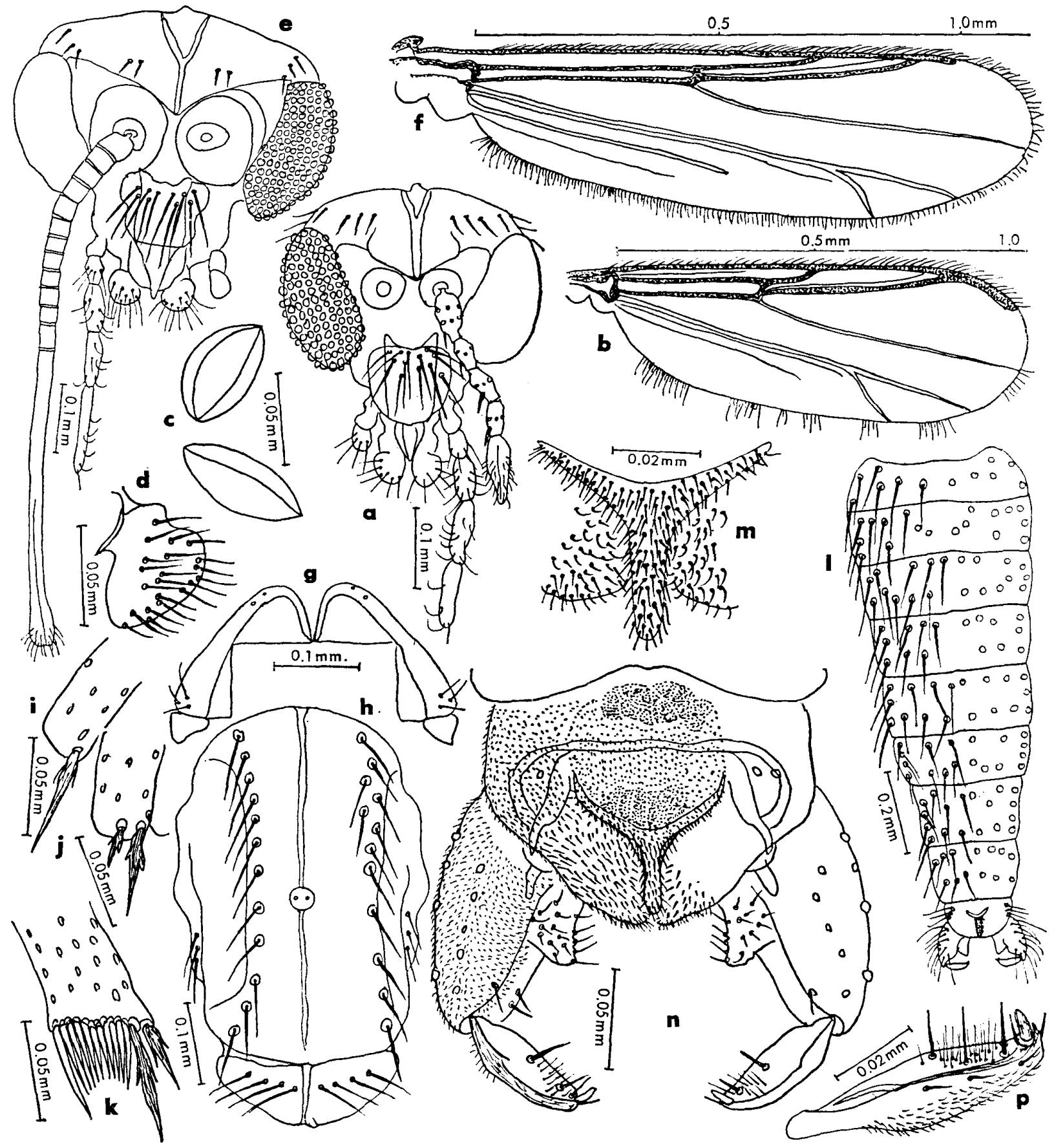

Fig. 5 Pscudosmittia ikemaensis, sp. nov.

Female: a, head; b, wing; $c$, spermathecae; d, cercus. Male: e, head; f, wing; g, antepronotum; $h$, scutum and scutellum; $i$, tip of front tibia; $j$, tip of middle tibia; $k$, tip of hind tibia; 1 , abdominal tergites; $\mathrm{m}$, anal point; $\mathrm{n}$, hypopygium; $\mathrm{p}$, gonostylus.

projection, ER 1.21-1.59 (1.40). Antenna with 13 flagellar segments, AR 1.19-1.37 $(1.27 \pm 0.06)$, AHR 0.49-0.56 (0.52), last segment slightly swollen apically, with numerous short sensory setae in the apical portion but without apical spine. Palp 4 segmented as usual. Supraorbital setae 1-3 in the inner portion and $3-5$ in the outer portion, $4-7$ in total. Clypeal setae $7-13$ (10.1). Antepronotum (Fig. 5-g) deeply separated in the middle, with 2 or 3 lateral setae. Scutum (Fig. 5-h) without dorsomedian setae but with a median tubercle bearing two minute setae. Dorsolateral setae $12-16(13.9)$, all arising from a large pale pit. Prealar setae 3-5 (most frequently 4 , 
mean 4.0). Scutellum with 8 setae in a transverse row in all the specimen examined. Wing in Fig. 5-f. Wing membrane bare, veins without macrotrichiae except on costa, slightly brownish. Squama bare, anal lobe obtuse. Costa extending beyond end of $\mathrm{R} 4+5$, which ends much proximal to the tip of wing and also to the end of Cul. $R 2+3$ ending closer to end of $R 4+5$ than to end of $\mathrm{R} 1, \mathrm{RR} 0.56-0.75(0.64)$. $\mathrm{fCu}$ is much distal to $\mathrm{r}-\mathrm{m}$, VR 1.66-1.83 (1.71), $\mathrm{Cu} 2$ is very short. $\mathrm{R} 4+5$ ending proximal to end of $\mathrm{Cu} 1, \mathrm{R} / \mathrm{Cu}$ 0.90-0.94 (0.92). Anal vein ending much proximal to fCu. fLR 0.54-0.58 (0.56), mLR 0.51-0.55 (0.53), hLR 0.65-0.68 (0.66), fTR 0.13-0.15 (0.14), fBR 4.0-5.1 (4.7), mBR 4.4-6.0 (5.2), hBR 4.4-6.1 (5.3). Front tibia with a long terminal spur ( $155 \mu \mathrm{m}$, Fig. 5-i). Middle tibia with a short $(22 \mu \mathrm{m})$ and a long $(42 \mu \mathrm{m})$ terminal spur (Fig. 5-j). Hind tibia with a long terminal spur $(48 \mu \mathrm{m})$, a short terminal spur $(27 \mu \mathrm{m})$, and a terminal comb composed of some 11 spurs 22-38 $\mu \mathrm{m}$ long (Fig. 5-k). In addition, tarsi I to IV of all legs with one short terminal spur. Pulvilli absent.

Abdominal tergites (Fig. 5-1) with reduced numbers of setae. Hypopygium in Fig. 5-n. Ninth tergite thickly covered with strong microtrichiae. Anal point long, slender, parallel-sided and apically rounded, darkly pigmented and also thickly covered with strong spines together with the $\mathrm{V}$-shaped base (Fig. 5-m). Inner lobe of gonocoxite single, roughly rectangular, with short setae on the dorsal side and with numerous microtrichiae on the ventral side. Gonostylus (Fig. 5-p) simple, almost straight but slightly expanded in the middle, with a large terminal spur.

Female (No. A 25A, 26A, B). BL 1.62, $1.80,1.90 \mathrm{~mm}$, WL $0.99,1.00,1.06 \mathrm{~mm}$. Ground color of scutum brown; stripes, scutellum and postnotum dark brown, abdominal tergites black, sternites yellowish brown; legs brown; halteres yellowish brown. Head in Fig. 5-a. Eyes bare, without dorsomedial projection and widely apart from each other, ER 1.26, 1.31, 1.37. Antenna composed of a pedicel and 5 flagellar segments $(65,47,48,40,84 \mu \mathrm{m})$, AR 0.42, 0.43 , AHR 0.30, 0.32. Supraorbital setae composed of 2 or 3 inner and 4 or 5 outer groups, clypeal setae 9, 11, 14. Antepronotum with 3 or 4 lateral setae. Scutum without dorsomedian setae but with a small round median tubercle bearing two minute setae. dl $12: 12,12: 13,16: 16$, pa $4: 4,4: 4$, $3: 5$, sc $8,8,10$. Wing in Fig. 5-b, generally similar in structure to that of male, but relatively wider: costa much more extending beyond end of $\mathrm{R} 4+5, \mathrm{R} 2+3$ almost fused with $\mathrm{R} 4+5$, RR $0.76,0.82$, 0.86. fCu much beyond $\mathrm{r}-\mathrm{m}, \mathrm{VR}$ extremely large, 1.49, 1.64, 1.66. $\mathrm{R} 4+5$ ending much proximal to end of Cu1. Cu2 very short. Squama bare, anal lobe obtuse. fLR $0.52,0.53, \mathrm{mLR} 0.51,0.51$, 0.53, hLR 0.64, 0.65, 0.67, fTR 0.14, 0.15, fBR 2.4, 2.6, 2.8, mBR 2.7, 2.9, 3.2, hBR $3.2,3.4,3.7$. Tarsi I to IV of all legs with a short terminal spur, as in male. Pulvilli absent. Spermathecae (Fig. 5-c) two, both ovoid and darkly pigmented. Cercus in Fig. 5-d.

Type specimens. Holotype: male, No. A 65:12a. Paratypes: 17 males and 3 females, No. A 65:09-14, 27, 29. All collected on February 3, 1982, on Ikema Island, Miyako, Okinawa.

Remarks. This species is also placed into the genus Pseudosmittia Goetghebuer, since eyes, wings and squama are all bare, scutum has a median tubercle, antenna without apical seta, and $\mathrm{R} 4+5$ is ending proximal to end of Cu1. Among the known species of this genus, it is somewhat related to $P$. curticosta (Edwards, 1929) in that gonocoxite has only one inner lobe, AR is about 1.0 , and hypopygium has well developed anal point. However, the present species differs from it essentially in the shape of gonostylus (widest at apex and produced inwards in curticosta), inner lobe of gonocoxite (much smaller in curticosta), and anal point (bearing stronger microtrichiae, with a large $\mathrm{U}$ shaped base in the present species). The present species is also quite unusual as a member of this genus in that costa is extending much beyond end of $\mathrm{R} 4+5$, and $\mathrm{fCu}$ is situated far distal to $\mathrm{r}-\mathrm{m}$. 


\section{Pseudosmittia nishiharaensis} Sasa et Hasegawa, sp. nov.

(Fig. 6-a-n)

A total of 16 males and a female were collected from 4 islands of the Ryukyus, all with insect net from bushes at the side of more or less polluted streams; 3 males and a female at Nishihara, Miyako Island (No. A $65: 21,22), 4$ males on Ikema Island, Miyako (No. A 65:13, 24), a male on Ishigaki (A 65:92), 4 males at Kochinda (A $65: 19,20$ ), and 4 males at Yara Bridge (A 65:83, 84), Kadena-cho, Okinawa Island, all in February 1982.

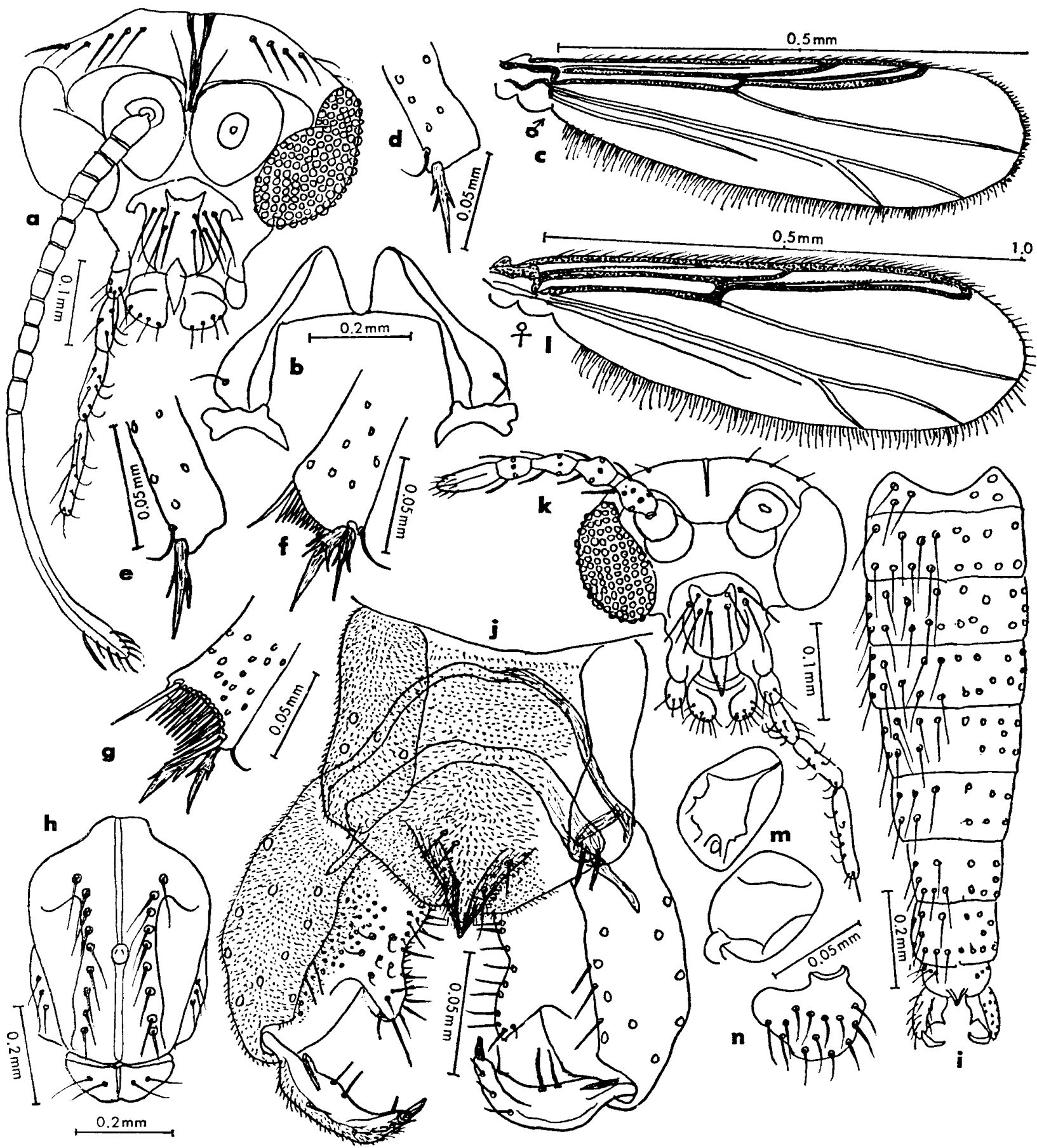

Fig. 6 Pseudosmittia nishiharaensis, sp. nov.

Male: $a$, head; b, antepronotum; c, wing; d, tip of front tibia; e, tip of middle tibia; $f, g$, tip of hind tibia; h, scutum and scutellum; i, abdominal tergites; j, hypopygium. Female: $\mathrm{k}$, head; 1 , wing; $\mathrm{m}$, spermathecae; $\mathrm{n}$, cercus. 
Male. BL $1.80-2.10(1.95 \pm 0.11$ in measurements of 10$) \mathrm{mm}$, WL 0.94-1.14 (1.07士 $0.07) \mathrm{mm}$. Ground color of scutum brownish yellow, stripes dark brown, scutellum, postnotum and abdominal tergites dark brown; halteres brown; femora dark brown, tibiae and tarsi brown. Head in Fig. 6-a. Median frontal process (Stirnfortsatz of Brundin, 1956 , p. 165) strongly extending between bases of antennae. Eyes bare, reniform and without dorsomedial projection, ER 1.371.67 (1.49). Antenna with 13 flagellar seg-

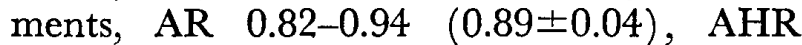
0.47-0.56 (0.52), last segment slightly expanded apically, without apical spur but with numerous short sensory setae in the apical portion. so 3-6 (most frequently 4 , mean 4.4), cl 6-9 (most frequently 6, mean 6.7).

Antepronotum (Fig. 6-b) deeply divided in the middle, usually with only one (2 in one, 0 in another) lateral seta on each side. Scutum and scutellum in Fig. 6-h. Scutum with a small pale area (Mesonotalhöcker of Brundin, 1956) in the middle, which bears two short setae, otherwise dorsomedian setae absent. dl 8-14 (most frequently 10, mean 10.4), pa 2-3 (mean 2.7), sc usually 4 (6 in one specimen). Wing in Fig. 6-c. Squama bare. Wing membrane without macrotrichiae, slightly brownish and very finely granular. $\mathrm{R} 4+5$ ending much proximal to tip of wing. Costa not extending beyond end of $R 4+5$. $R 2+3$ running very close to $\mathrm{R} 4+5$, often almost fused with it, $\mathrm{RR}$ $0.65-0.84(0.75)$. Tip of $\mathrm{R} 4+5$ much proximal to tip of Cu1, R/Cu 0.83-0.92 (0.88). $\mathrm{fCu}$ situated far distal to $\mathrm{r}-\mathrm{m}, \mathrm{VR}$ unusually large, $1.50-1.71$ (1.63). Cu2 very short, almost straight. Anal vein ending much proximal to fCu. Anal lobe obtuse.

Tip of front tibia with a long and basally barbed terminal spur $(43 \mu \mathrm{m}$; Fig. 6-d $)$. Tip of middle tibia with only one, relatively long terminal spur (35 $\mu \mathrm{m}$, Fig. 6-e). Tip of hind tibia with a long terminal spur (42 $\mu \mathrm{m})$, a shorter terminal spur $(28 \mu \mathrm{m})$, and a terminal comb composed of some 12 free spurs 23-32 $\mu \mathrm{m}$ long (Fig. 6-f, g). fLR 0.480.51 ( 0.49 , unusually small), mLR $0.48-0.52$ (0.51), hLR 0.57-0.59 (0.58), fTR 0.12$0.13(0.12)$. Tarsi with long beards, fBR 3.0-5.0 (4.0), mBR 3.7-5.9 (4.2), hBR 4.7-5.4 (5.1). Pulvilli absent, tarsi IV cylin- drical, almost as long as tarsi $\mathrm{V}$ of the same legs.

Setae on abdominal tergites are reduced in the numbers, as in Fig. 6-i. Hypopygium in Fig. 6-j. Ninth tergite produced caudally in the middle forming a V-shaped anal point, whose lateral ridges are darkly pigmented, leaving the middle portion clear. Inner lobe of gonocoxite longer than wide, with rather pointed apex. Gonostylus long and narrow, inner margin concave and with two long setae, with a large apical spur but without subapical swelling.

Female. BL $1.70 \mathrm{~mm}$, WL $1.00 \mathrm{~mm}$. Ground color of scutum yellow, scutal stripes, scutellum and postnotum dark brown, halteres yellowish brown, leg segments yellowish brown, abdominal tergites dark brown, sternites yellow. Head in Fig. 6-k. Eyes bare, inner margin slightly concave, ER 1.41. Antenna with 5 flagellar segments (65, 40, $42,40,66 \mu \mathrm{m})$, AR 0.35, so 5, 5, cl 9. Scutum without dorsomedian setae, with a median tubercle bearing two minute setae, dorsolateral setae $11: 12$, prealar setae $3: 3$, scutellar setae 6. Wing in Fig. 6-1. Squama bare, anal lobe obtuse. Costa not extending beyond end of $R 4+5, R 2+3$ close to $R 4+5$, RR 0.68. fCu much beyond $\mathrm{r}-\mathrm{m}, \mathrm{VR} 1.73$ (unusually high, as in male). $\mathrm{R} 4+5$ ending proximal to end of $\mathrm{Cu} 1(\mathrm{R} / \mathrm{Cu}$ ratio 0.93$)$. Spermathecae two, both almost colorless, $66 \times 50,72 \times 40 \mu \mathrm{m}$ (Fig. $6-\mathrm{m}$ ). Cercus with a ventral projection, $62 \mu \mathrm{m}$ high and $46 \mu \mathrm{m}$ wide (Fig. 6-n).

Type specimens. Holotype: male, No. A 65:22a, collected at Nishihara, Miyako Island. Paratypes: 15 males and a female, collected on 4 islands of the Ryukyus, as stated before.

Remarks. This species is also placed into the genus Pseudosmittia Goetghebuer, 1932, in the sense of Brundin (1956) and Pinder (1978), since eyes, wings and squama are all bare, antenna has no apical seta, $\mathrm{R} 4+5$ is ending proximal to end of $\mathrm{Cu1}$, costa is not extending beyond end of $\mathrm{R} 4+5$, scutum has no dorsomedian setae but has a median tubercle (Mesonotalhöcker of Brundin, 1956). However, it is quite unusual as a member of this genus in that $\mathrm{fCu}$ is situated much distal to $r-m$ with very high VR values of $1.50-1.71$, and $\mathrm{Cu} 2$ is very short and 
not sinuate. The genus Pseudosmittia includes fairly large number of species. Brundin (1956) recorded 7 species from North Europe, and Pinder (1978) 6 species from British Isles. Among them, the present species is related to $P$. restricta Brundin, 1956, in that pronotum is widely separated in the middle, wing veins without macrotrichiae, gonocoxite with only one inner lobe, and $\mathrm{R} 2+3$ is almost fused with $\mathrm{R} 4+5$, but is essentially different from it in that the present species has a large conical anal point on ninth tergite (it is absent in restricta), $\mathrm{AR}$ being larger (only 0.25 in restricta), and gonostylus is swollen apically in restricta. The present species is also quite unusual as a member of subfamily Orthocladiinae in that middle tibia has only one apical spur (most other species have two short apical spurs on middle tibia). In Japan, Sasa (1985c, p. 124) recorded Pseudosmittia triappendiculata (Goetghebuer, 1931) from Lake Motosu and Yamanaka (Yamanashi), but in this species gonocoxite has three inner lobes and thus belongs to an entirely different group within this genus.

\section{Smittia aterrima (Meigen, 1818)}

A male was collected at Kochinda, Okinawa Island, on January 28, 1982, with insect net from bush near a sewage stream (No. A 65:94A). Body largely dark brown, scutal stripes black. BL $2.96 \mathrm{~mm}$, WL 1.79 $\mathrm{mm}$ (both larger than in $S$. nudipennis). AR 1.85, AHR 0.61, ER 1.11, so 9:10, cl 6, pn $4: 4$, dm 14, dl 10:13, pa $4: 5$, sc 6 , sq $0: 0$. RR 0.31, VR 1.34, R/Cu 1.05, fLR 0.55, mLR 0.48, hLR 0.60, fTR 0.11, fBR 3.2, mBR 3.2, hBR 7.9. Pulvilli absent. Hypopygium as illustrated by Sasa (1985c, p. 144).

Remarks. This species is widely distributed in Europe, and its morphology was described by Edwards (1929, p. 360), Goetghebuer (1940, p. 86), and Pinder (1978, p. 96). In Japan, it was also recorded by Tokunaga (1940, p. 289) from Hokkaido, by Sasa (1985c, p. 121) from Lakes Motosu and Yamanaka (Yamanashi), by Sasa and Kamimura (1987) from Lake Akan (Hokkaido), and by Sasa and Kawai (1987a) from Lake Biwa (Shiga). Morphologically, it is characterized by having relatively large body size, pubescent eyes, short anal point with microtrichiae towards the tip, small but acutely produced inner lobe of gonocoxite, and simple gonostylus with a large swelling in the middle.

\section{Smittia nudipennis Goetghebuer, 1931}

A male was collected with insect net on the bank of the Hija River under Yara Bridge, Okinawa Island, on December 11. 1981 (No. A 65:82A). Body largely black except abdominal sternites which are brown. BL $2.94 \mathrm{~mm}$, WL $1.28 \mathrm{~mm}$. Both antennae are missing. Eyes pubescent, ER 1.38. so $5: 5$ (none in the middle portion, all situated laterally), $\mathrm{cl} 8, \mathrm{pn} 1: 1, \mathrm{dm} 6$ (all small, arising from near anterior margin of scutum), dl 16:19 (more numerous than in the related species), pa $8: 8$, sc 10 , sq $0: 0$. RR 0.44, VR 1.28, R/Cu 0.94 (characteristic to this species), fLR 0.48 (smaller than in the related species), mLR 0.44 , hLR $0.5 \%$. fTR 0.13, fBR 3.1, mBR 4.0, hBR 5.0. pulvilli absent. Hypopygium as illustrated by Sasa (1985c, p. 144).

Remarks. This is a species widely distributed in Europe, and its morphology was described by Goetghebuer (1940, p. 97) and Pinder (1978, p. 96). In Japan, it was recorded by Sasa (1985c, p. 122) from Lakes Motosu, Shoji and Yamanaka (Yamanashi), by Sasa and Kamimura (1987, p. 41) from Lake Panke (Hokkaido), and by Sasa and Kawai (1987a, p. 53) from Lake Biwa (Shiga). Morphologically, this species is characterized by having relatively small body size, pubescent eyes, flat anal lobe of wing, $R 4+5$ ending proximal to end of $\mathrm{Cu} 1$ ( $\mathrm{R} / \mathrm{Cu}$ smaller than 1.0), long, nude and apically pointed anal point, and gonostylus being strongly swollen in the middle.

\section{Smittia pratorum (Goetghebuer, 1926)}

(Fig. 7-a-m)

Eight males and 2 females were collected at Tamagusuku, 3 males and a female at Ryutan, 2 males at Hentona, all on Okinawa Island; a male at Ishigaki, Ishigaki Island, in January and February, 1982 (No. A 

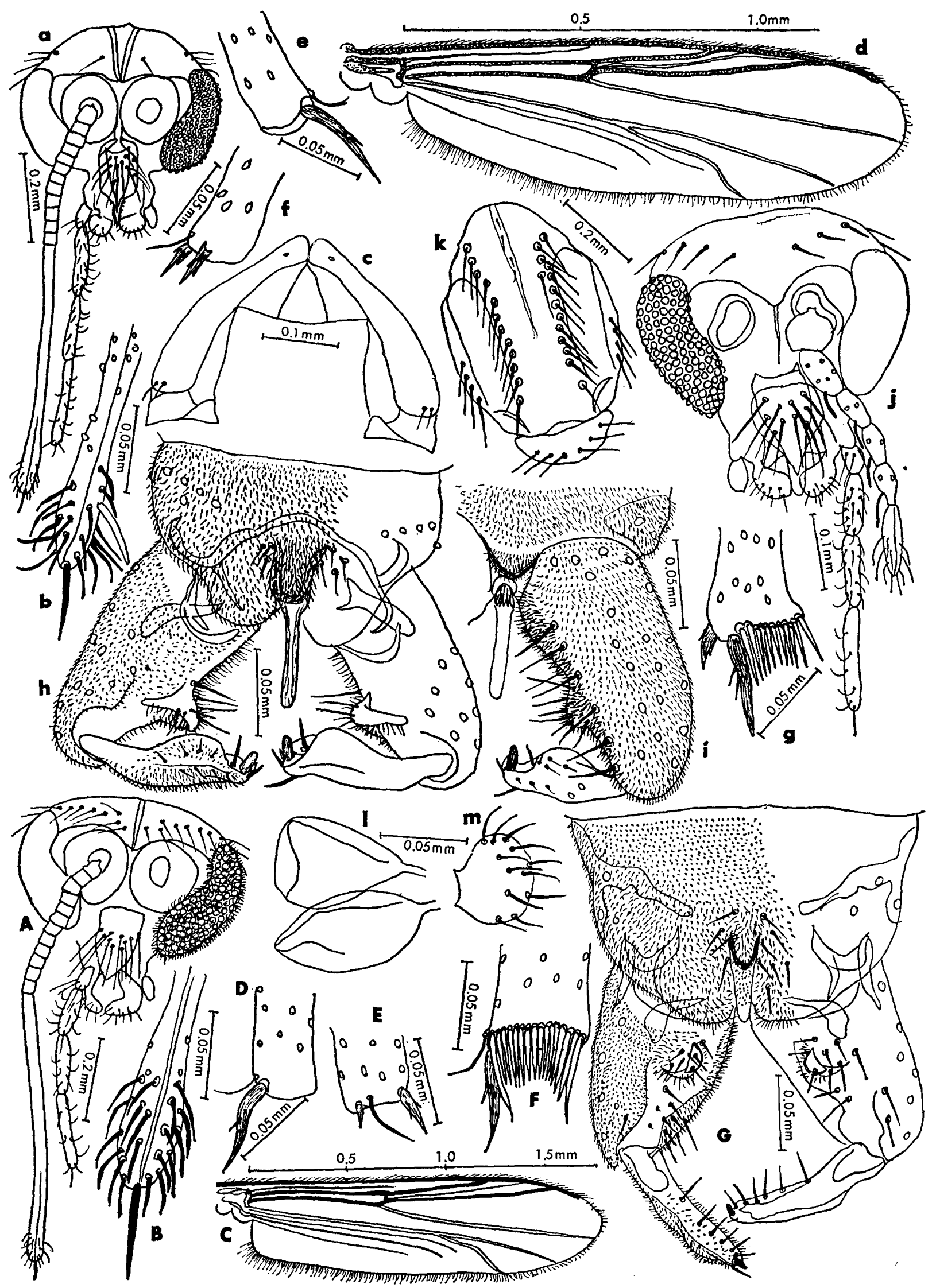

Fig. 7 
65:01-07, 32, 33, 74, 91).

Male. BL 2.02-2.30 (2.12 in average of $10) \mathrm{mm}$, WL $1.25-1.58 \quad(1.44) \mathrm{mm}$. Body largely black or dark brown. Ground color of scutum dark brown, scutal stripes black; scutellum, postnotum and abdominal tergites black; leg segments dark brown; halteres brown. Head in Fig. 7-a. Eyes bare (a very important characteristic of this species), reniform, ER 1.24-1.45 (1.49). Antenna composed of a pedicel and 13 flagellar segments, AR 1.40-1.j4 (1.49), AHR 0.49-0.56 (0.54), last segment slightly expanded in the apical portion, with a strong apical seta, and some 10 short and curved sensory setae in the apical portion (Fig. 7-b). Supraorbital setae composed of one or two middle pairs, and 3-6 lateral pairs, cl 7-14 (9.8). Antepronotum (Fig. 7-c) united in the middle, with 1 or 2 lateral setae. $\mathrm{dm} 6-10$, all minute. dl 8-14 (most frequently 12, mean 12.0 ), pa $3-5$ (most frequently 3 , mean 3.8 ), scutellar setae 6 (in 7 specimens) or 8 (in 3 specimens, mean 7.2), in a transverse row.

Wing in Fig. 7-d. Squama bare, anal lobe obtuse. R2+3 ending closer to end of R1 than to end of R4+5, RR 0.27-0.36 (0.31). Costa extending much beyond end of $\mathrm{R} 4+5$. fCu much beyond r-m, VR 1.28-1.40 (1.30). Tip of Cu1 slightly proximal to tip of $\mathrm{R} 4+5$, $\mathrm{R} / \mathrm{Cu} 1.02-1.11$ (1.05). Cu2 strongly curved in the middle. Anal vein extends beyond fCu. Front tibia with a long terminal spur ( $50 \mu \mathrm{m}, 1.8$ times the diameter of the end of front tibia, Fig. 7-e). Middle tibia with two short terminal spurs $(23,24 \mu \mathrm{m}$, Fig. 7-f). Hind tibia expanded at tip, with a long terminal spur $(50 \mu \mathrm{m})$, a short terminal spur $(23 \mu \mathrm{m})$, and a terminal comb composed of 12 free spurs (23-33 $\mu \mathrm{m}$, Fig. 7-g). fLR $0.53-0.55$ (0.54), mLR 0.43-0.47 (0.45), hLR 0.54-0.58 (0.56), fTR $0.12-$ 0.13 (0.12), fBR 2.8-4.4 (3.5), mBR 3.5-7.0 (5.4), hBR 4.0-7.7 (6.5). Pulvilli absent, claws and empodium well developed. All tarsi without terminal spurs.
Hypopygium in Fig. 7-h. i. Anal point long, nearly parallel-sided and with rounded apex, without microtrichiae, and with a conspicuous U-shaped base. Inner lobes of gonocoxite double, the dorsal lobe triangular and without microtrichiae, the ventral lobe broad and obtuse, bearing both macro- and microtrichiae. Gonostylus strongly expanded in the middle and with a large terminal spur. Small virga present.

Female (measurements of 3 specimens). BL 1.48, 1.60, $1.84 \mathrm{~mm}$, WL 1.12, 1.14, 1.24 $\mathrm{mm}$. Body largely dark brown, generally paler than in male. Head in Fig. 7-j. Eyes reniform, ER 1.07, 1.07, 1.17. Antenna with 5 flagellar segments, last segment 0.35 .0 .38 times as long as the 4 preceding segments combined. Supraorbital setae composed of 1 or 2 inner group and 4 or 5 lateral group. cl 8, 8, 12. Antepronotum united in the middle, with 1 or 2 lateral setae on each side. Scutum and scutellum in Fig. 7-k. $\operatorname{dm} 6,6,6$, dl 10:10, 12:14, 16:16, pa $4: 4$, $4: 4,5: 6$, sc 6, 6, 7. Squama bare. Costa extending much beyond end of $\mathrm{R} 4+5$, to almost tip of the wing. RR $0.36,0.40,0.42$, VR 1.21, 1.42, R/Cu 1.02. 1.08. Cu2 strongly sinuate. fLR $0.52,0.54 .0 .55$, mLR 0.44 , 0.45 , hLR $0.57,0.58,0.60$. fTR $0.14,0.14$, 0.14, fBR 2.7, 2.8, 3.5, mBR 2.6, 3.0, hBR 2.7, 4.3, 4.5. Pulvilli absent. Spermathecae in Fig. 7-1. Cercus (Fig. 7-m) small and nearly circular.

Remarks. This species was collected on the shore of eutrophicated ditches and lakes on Okinawa and Ishigaki Islands. These specimens are morphologically almost coincident with that of $S$. pratorum described by Edwards (1929, p. 361), Goetghebuer (1940, p. 97) and Pinder (1978. p. 96), especially in that eyes are nude and male hypopygium has a long and nude anal point. This species is morphologically related to $S$. itachipennis Sasa et Kawai, 1987, recorded from Toyama, Japan, but the eyes are pubescent in the latter.

Fig. 7 Smittia pratorum (Goetghebuer) and Smittia gusukuensis, sp. nov.

Smittia pratorum (Goetghebuer). Male: a, head; b, tip of antenna; c, antepronotum; $d$. wing; e, tip of front tibia; $f$, tip of middle tibia; $g$, tip of hind tibia; h, hypopygium, dorsal view; i, do, right half, ventral view. Female: $j$, head; $k$, scutum and scutellum; 1. spermathecae; $m$, cercus. Smittia gusukuensis, sp. nov. Male: A, head; B, tip of antenna: C, wing; D, tip of front tibia; E, tip of middle tibia; F, tip of hind tibia; G, hypopygium. 


\section{Smittia gusukuensis Sasa et Hasegawa, sp. nov.}

(Fig. 7-A-G)

A male (holotype) was collected on January 28, 1982, at Tamagusuku, Okinawa Island. Holotype: No. A 65:04a.

Male. BL $3.05 \mathrm{~mm}$, WL $1.79 \mathrm{~mm}$. Body largely black and dark brown; scutum entirely black, scutellum dark brown, postnotum black, abdominal tergites dark brown, halteres and leg segments dark brown. Head in Fig. 7-A. Eyes pubescent, inner margin conspicuously concave, ER 1.08. Antenna with 13 flagellar segments, AR 1.86, AHR 0.55. Tip of antenna slightly expanded, and with a strong terminal seta and numerous short and curved setae (Fig. 7-B). so 10:10, cl 10. Antepronotum well developed and thickly united in the middle, with $6: 6$ lateral setae. $\mathrm{dm} 12$ in two rows, all minute and arising from near anterior margin of scutum. dl $8: 9$, pa $3: 3$, sc 8 . Wing in Fig. 7-C. Squama bare, anal lobe nearly rectangularly produced. Costa produced much beyond end of $\mathrm{R} 4+5$. RR 0.36 , VR 1.34 (unusually high). R4+5 ending above tip of $\mathrm{Cu} 1, \mathrm{R} / \mathrm{Cu}$ 1.00. $\mathrm{Cu} 2$ strongly curved. Anal vein extending beyond fCu. Front tibia with a long terminal spur $(52 \mu \mathrm{m})$. Middle tibia with two terminal spurs $(17,32 \mu \mathrm{m})$. Hind tibia with a long terminal spur $(58 \mu \mathrm{m})$, a short terminal spur $(22 \mu \mathrm{m})$, and a terminal comb composed of 15 free spurs $(26-46 \mu \mathrm{m})$. fLR 0.54, mLR 0.45, hLR 0.60, fTR 0.12, fBR 3.3, mBR 3.8, hBR 5.2. Pulvilli absent.

Hypopygium in Fig. 7-G. Anal point rather small and covered with microtrichiae to near tip, such as in that of $S$. aterrima, and with a darkly pigmented, U-shaped base. Inner lobe of gonocoxite single and very small, roughly semicircular. Gonocoxite bearing some 10 short setae on inner side around inner lobe. Gonostylus simple, long, slender and tapering towards pointed apex, with a small terminal spur, a small subterminal tooth, but without swelling in the middle such as seen in $S$. aterrima.

Remarks. This species is somewhat related to $S$. aterrima (Meigen) in that eyes are pubescent, and anal point is rather short and almost entirely covered by microtrichiae, but both differ from each other in the shape of gonostylus (inner margin strongly expanded in aterrima, inner margin is concave and not expanded in the present species), and of inner lobe of gonocoxite (narrow triangular and apically pointed in aterrima, wide and rounded in the present species).

\section{Paramerina divisa (Walker, 1856)}

(Fig. 8-a-m)

Altogether 5 males and a female emerged from bottom sediments of Lake Ryutan, collected on December 7, 1981 (No. A 65:35a, b, 36a, b, 42, 43). Two pupal exuviae associated with males were also collected and studied (No. A 65:37a, b).

Male. BL 2.96-3.22 (3.07 in average of 5) $\mathrm{mm}$, WL 1.66-1.84 (1.58) mm. Body largely yellow, with brown marks; scutum with yellow ground color, median and lateral stripes yellowish brown, and with a pair of yellow marks posterior to the lateral stripes; scutellum yellow, postnotum yellowish brown, halteres pale yellow, wing unmarked, leg segments entirely yellow; abdominal tergite I brown, II and V entirely yellow, III, IV, VI and VIII brown for oral half and yellow for distal half, VII and hypopygium yellowish brown. Head in Fig. 8-a. Eyes each with a long dorsomedial projection, ER 0.19-0.34 $(0.28)$, without microtrichiae. Antenna composed of a pedicel, 12 short proximal segments, a long 13th segment, and a short apical segment bearing a stout terminal seta and several short sensory setae, AR (combined length of last and penultimate segments divided by the combined length of flagellar segments I-XII) 1.71-1.90 (1.79), AHR $0.49-0.56(0.53)$. so $14-18$ (15.2) on one side, cl 13-16 (15.0). Base of antenna with 4-6 (mean 4.8) long setae on each side.

Antepronotum well developed, united in the middle, without dorsal setae and with 2-3 (usually 3, mean 2.9) lateral setae. Distribution of setae on scutum and scutellum in Fig. 8-b. dm 40-52 (46.0), dl 30-34 (31.9), pa 9-13 (10.6), all composed of the long and the short setae. Scutellum with 10-12 (11.0) long setae in a caudal transverse row, and 16-22 (18.8) short setae in oral area. Wing in Fig. 8-c. Squama with 18-26 (21.2) fringe hairs. Wing membrane 


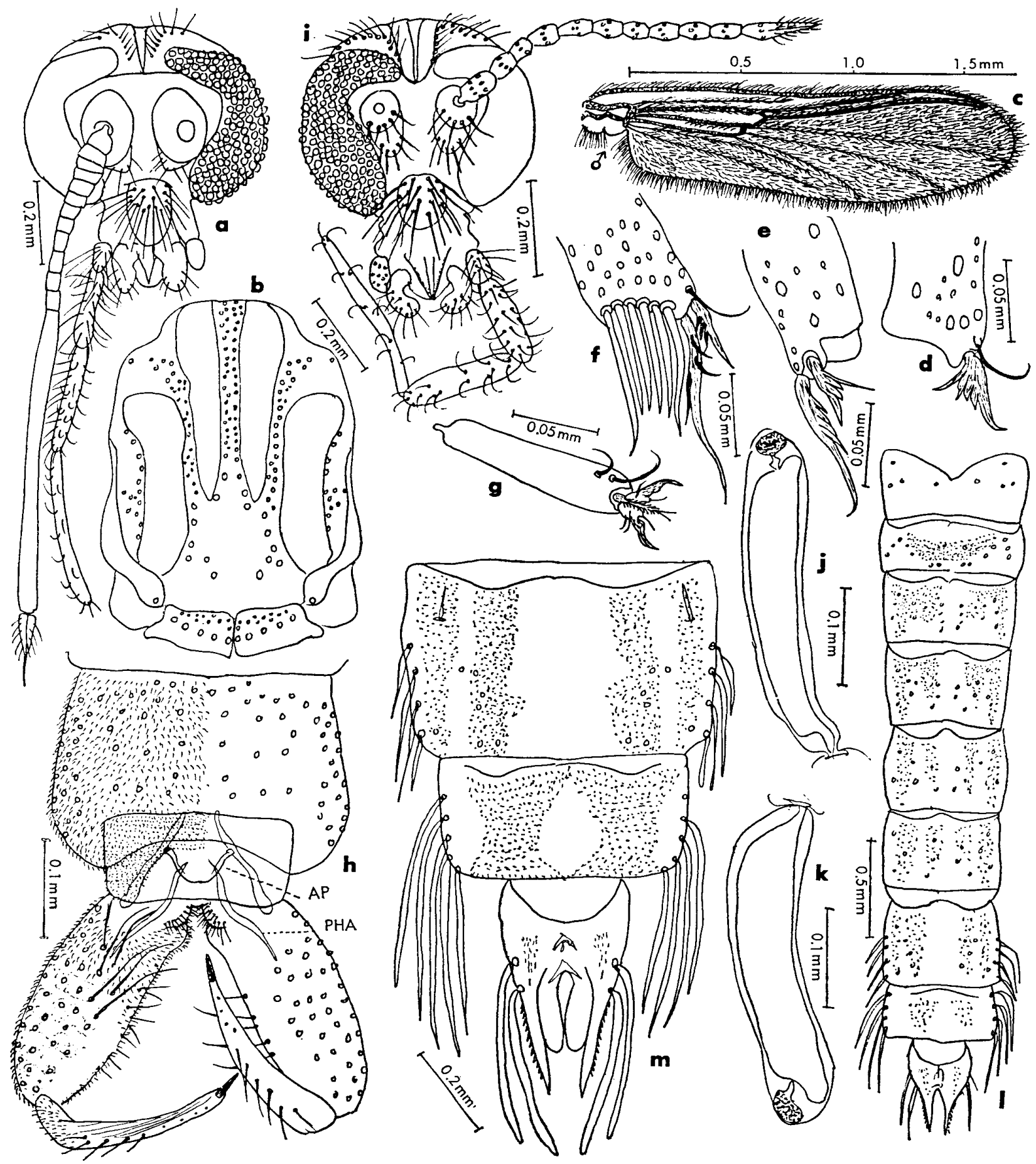

Fig. 8 Paramerina divisa (Walker).

Male: $a$, head; b, scutum and scutellum, showing distribution of setae; $c$, wing; $d$, tip of front tibia; e, tip of middle tibia; $f$, tip of hind tibia; $g$, hind tarsus $V$; $h$, hypopygium. Female: i, head. Pupa: j, k, thoracic horn; 1 , abdominal tergites; $m$, tergites VII, VIII and anal tergite.

thickly covered with macrotrichiae. Costa not produced beyond end of $\mathrm{R} 4+5$, ending proximal to end of $\mathrm{M}$ and distal to end of $\mathrm{Cu} 1, \mathrm{R} / \mathrm{Cu} 1.03-1.08$ (1.05). R1 and R4+5 running closely, $\mathrm{R} 2+3$ absent. Cross vein $\mathrm{m}$-cu situated distal to $\mathrm{fCu}$ and united with
Cu1. fCu proximal to $\mathrm{r}-\mathrm{m}$, VR $0.74-0.84$ $(0.80)$. Anal vein extending much beyond fCu.

Front tibia with a rather short, barbed terminal spine (Fig. 8-d). Middle tibia with a long and a short terminal spines, both 
barbed (Fig. 8-e). Hind tibia with a very long and narrow terminal spur, a short terminal spur, and a terminal comb composed of 6 simple and free spurs (Fig. 8-f). fLR 0.69-0.91 (0.78), mLR 0.98-1.03 (1.00), hLR 0.79-0.85 (0.82), fTR 0.14-0.15 (0.14), fBR 5.2-7.9 (6.5), mBR 6.0-7.8 (6.6), hBR 6.8-7.8 (7.4). Tarsi $V$ with a pair of well developed claws, a rather small empodium, and without pulvilli (Fig. 8-g).

Hypopygium in Fig. 8-h. Ninth tergite small and almost quadrangulate. Anal point (AP) broad, transparent and roughly triangular, with rounded apex. Phallapodeme (PHA) very long and extending into gonocoxite (a characteristic of this genus). Gonocoxite with a setigerous area at the base but without basal lobe. Gonostylus long, slender, widest at base and tapering towards apex, with a long apical spur.

Female. WL $1.58 \mathrm{~mm}$. Body coloration as in male, largely yellow, with yellowish brown marks on scutum. Head in Fig. 8-i. Antenna composed of a pedicel and 11 flagellar segments, with 5 setae on each of the base and the pedicel. Palp 4 segmented. so $14: 16, \mathrm{cl} 15$. Antepronotum complete, with 2:2 lateral setae. dm 62, dl 56:59, pa $12: 12$, sc 30 , sq $18: 21$. Wing membrane thickly covered with macrotrichiae, $\mathrm{R} 2+3$ absent. $\mathrm{r}-\mathrm{m}$ distal to $\mathrm{fCu}, \mathrm{VR} 0.88$. $\mathrm{m}-\mathrm{cu}$ distal to $\mathrm{fCu}$. Costa not extending beyond end of $R 4+5$, which is slightly distal to end of $\mathrm{Cu} 1, \mathrm{R} / \mathrm{Cu}$ 1.04. fLR 0.74 , mLR 0.88, hLR 0.79, fTR 0.15, fBR 4.4, mBR 4.7, hBR 5.2. Abdomen missing from this specimen.

Pupa. Length of abdomen 2.82, $3.12 \mathrm{~mm}$. Thoracic respiratory horns (Fig. 8-j, k) nearly cylindrical, 272-288 $\mu \mathrm{m}$ long and 48-50 $\mu \mathrm{m}$ wide, composed of a long dark tube with a small fan-like organ enclosed in a transparent sheath. Distribution of setae and spines on abdominal tergites in Fig. 8-1. Tergites I to IV without lateral swimming hairs, VII with 4 pairs, VIII with 5 pairs of long, flat swimming hairs. Anal lobe very narrow and slender, with two pairs of lateral swimming hairs, and small spines along lateral margin (Fig. 8-m).

Remarks. This species belongs to the genus Pentaneura Philippi, 1865 in the sense of Edwards (1929) and Tokunaga (1937a, b), and to Paramerina Fittkau, 1962 in the more modern sense, since wing vein $R 2+3$ is absent, $\mathrm{m}$-cu is distal to $\mathrm{fCu}$, costa is not extending beyond end of $\mathrm{R} 4+5$ and ending proximal to tip of $M$, gonocoxite has no basal lobe, and hypopygium has very long phallapodemes. Among the previously recorded species of this group, the present specimens are identified here as $P$. divisa (Walker) described by various workers in Europe, by Edwards, 1929, as Pentaneura, by Goetghebuer (1937), as Ablabesmyia, by Fittkau (1962) and Pinder (1978), as Paramerina divisa (Walker). In Japan, Tokunaga $(1937 \mathrm{a}, \mathrm{b})$ recorded this species from Gotenba (Shizuoka) by a name of Pentaneura divisa, and Fittkau (1962, p. 327) quoted it as "(?) Paramerina divisa Tokunaga, 1937."

\section{Clinotanypus sugiyamai Tokunaga, 1937}

A male emerged from a bottom sample collected in an eel-pond at Hentona, Okinawa Island, on December 10, 1981 (No. A 65:38). The standard measurement data are as follows.

BL $5.28 \mathrm{~mm}$, WL $2.44 \mathrm{~mm}$, AR 2.86, AHR 0.54 , ER 0.42 , so $16: 16, \mathrm{cl} 8, \mathrm{dm} 82, \mathrm{dl}$ $44: 46$, pa $31: 33$, sc 44 , sq $32: 32$, RR 0.49 , VR 1.04, R/Cu 1.18, fLR 0.65, mLR 0.72, hLR 0.70, fTR 0.11, fBR 2.0, mBR 2.4, hBR 3.7.

Remarks. This species was described by Tokunaga (1937a) based on males collected in Kyoto. Redescription of the male and the new record of female was made by Sasa and Kawai (1987a) with specimens collected on the shore of Lake Biwa.

\section{Acknowledgements}

Thanks are due to Professor M. Otsuru, former Dean of the School of Medicine, University of the Ryukyus, and members of the Department of Parasitology, University of the Ryukyus, for their valuable assistances and collaborations.

\section{REFERENCES}

Brundin, L. (1956): Zur Kenntinis der schwedischen Chironomiden. Ark. Zool., 39: 1-95. Edwards, F. W. (1929): British non-biting midges 
(Diptera, Chironomidae). Trans. R. Entomol. Soc. London, 77: 279-429.

Fittkau, E. J. (1962) : Die Tanypodinae (Diptera, Chironomidae). Abh. Larvalsystematik Insekten, Nr. 6: 1-453.

Goetghebuer, M. (1937): 13c. b) Subfamilie Tendipedinae (Chironominae). In: Die Fliegen der Palaearktischen Region, pp. 1-136.

Goetghebuer, M. (1940): 13g. f) Subfamilie Orthocladiinae. In: Die Fliegen der Palaearktischen Region, pp. 1-208.

Goetghebuer, M. (1936): 13b. Tendipedidae (Chironomidae), a) Subfamilie Pelopiinae (Tanypodinae). In: Die Fliegen der Palaearktischen Region (ed., Lindner, E.), pp. 1-50.

Hasegawa, H. and M. Sasa (1987): Taxonomical notes on the chironomid midges of the tribe Chironomini collected from the Ryukyu Islands, Japan, with description of their immature stages. Jpn. J. Sanit. Zool., 38: 275-295.

Pinder, L. C. V. (1978): A key to adult males of British chironomidae. 1. Freshwater Biol. Assoc. Publ., No. 37: 1, 1-162; 2, Figs. 77-184.

Reiss, F. and E. J. Fittkau (1971): Taxonomie und Oekologie europaeisch verbreiteter Tanytarsus-Arten (Chironomidae, Diptera). Arch. Hydrobiol. (Suppl.), 45: 212-304.

Saether, O. A. (1975): Twelve new species of Limnophyes Eaton, with keys to Nearctic males of the genus (Diptera, Chironomidae). Can. Entomol., 107: 1029-1056.

Saether, O. A. (1980): Glossary of chironomid morphology terminology (Diptera, Chironomidae). Entomol. Scand. (Suppl.), 14: 5-51.

Sasa, M. (1979): A morphological study of adults and immature stages of 20 Japanese species of the family Chironomidae (Diptera). Res. Rep. Natl. Inst. Environ. Stud., No. 7: 1-148.

Sasa, M. (1980): Studies on chironomid midges of the Tama River. Pt. 2. Description of 20 species of Chironominae recovered from a tributary. Res. Rep. Natl. Inst. Environ. Stud., No. 13: 9-107.

Sasa, M. (1981a): Studies on chironomid midges of the Tama River. Pt. 3. Species of the subfamily Orthocladiinae recorded at the summer survey and their distribution in relation to the pollution with sewage waters. Res. Rep. Natl. Inst. Environ. Stud., No. 29: 1-78.

Sasa, M. (1981b): Studies on chironomid midges of the Tama River. Pt. 4. Chironomidae recorded at a winter survey. Res. Rep. Natl. Inst. Environ. Stud., No. 29: 79-148.

Sasa, M. (1983a): Studies on chironomid midges of the Tama River. Part 5. An observation on the distribution of Chironominae along the main stream in June, with description of 15 new species. Res. Rep. Natl. Inst. Environ. Stud.,
No. 43: 1-67.

Sasa, M. (1983b) : Studies on chironomid midges of the Tama River. Part 6. Description of species of the subfamily Orthocladinae recovered from the main stream in the June survey. Res. Rep. Natl. Inst. Environ. Stud., No. 43: 69-99.

Sasa, M. (1984): Studies on chironomid midges in lakes of the Nikko National Park. Pt. II. Taxonomical and morphological studies on the chironomid species collected from lakes in the Nikko National Park. Res. Rep. Natl. Inst. Environ. Stud., No. 70: 16-215.

Sasa, M. (1985a): Studies on chironomid midges of some lakes in Japan. Part 1. A report on the chironomids collected in winter from the Sapporo area, Hokkaido. Res. Rep. Natl. Inst. Environ. Stud., No. 83: 1-23.

Sasa, M. (1985b): Studies on chironomid midges of some lakes in Japan. Part 2. Studies on the chironomids collected from lakes in Southern Kyushu. Res. Rep. Natl. Inst. Environ. Stud., No. 83: 25-99.

Sasa, M. (1985c): Studies on chironomid midges of some lakes in Japan. Part 3. Studies on the chironomids collected from lakes in the Mount Fuji area. Res, Rep. Natl. Inst. Environ. Stud., No. 83: 101-160.

Sasa, M. and H. Hasegawa (1983): Chironomid midges of the tribe Chironomini recovered from sewage ditches, eutrophicated ponds and clean streams of the Ryukyu Islands, southern Japan. Jpn. J. Sanit. Zool., 34: 305-341.

Sasa. M. and K. Ichimori (1983): Studies on chironomid of the Tama River. Part 7. Additional species collected in winter from the main stream. Res. Rep. Natl. Inst. Environ. Stud., No. 43: 101-122.

Sasa, M. and K. Kamimura (1987): Chironomid midges collected on the shore of lakes in the Akan National Park, Hokkaido (Diptera, Chironomidae). Res. Rep. Natl. Inst. Environ. Stud., No. 104: 9-61.

Sasa, M. and K. Kawai (1987a): Studies on the chironomid midges of Lake Biwa. Lake Biz'a Stud. Monogr., No. 3: 1-119.

Sasa, M. and K. Kawai (1987b): Studies on the chironomid midges of the Stream Itachigawa, Toyama. Bull. Toyama Sci. Mus., No. 10: 2572.

Tokunaga, M. (1937a): Chironomidae from Japan. IX. Tanypodinae and Diamesinae. Philipp. J. Sci., 62: 21-65.

Tokunaga, M. (1937b): Family Chironomidae (Fauna Nipponica) (Nihon Dobutsu Bunrui), 10, Fasc. 7, No. 1, 1, 1-110 (in Japanese).

Tokunaga, M. (1938): Chironomidae from Japan. X. New or little known midges, with descriptions of the metamorphoses of several 
species. Philipp. J. Sci., 65: 318-383.

Tokunaga, M. (1939): Chironomidae from Japan. XI. New or little known midges, with special references to the metamorphoses of torrential species. Philipp. J. Sci., 69: 297-345.

Tokunaga, M. (1940): Chironomidae from Japan. XII. New or little known Ceratopogonidae and Chironomidae. Philipp. J. Sci., 72: 255317.

Townes, H. K., Jr. (1945): The Nearctic species of Tendipedini (Diptera, Tendipedidae $=$ Chironomidae). Am. Midl. Nat., 34: 1-206.

\section{摘 要}

琉球列島に生息するユスリカ類の知見追加

琉球列島に産するユスリカ科の昆虫については，す でに Sasa and Hasegawa (1983) が Chironominae 亜科の Chironomini 族の26種の成虫の記録を行い, さらに Hasegawa and Sasa (1987) はその中の11種 のサナギと 8 種の幼虫の形態を記載し, かつ 4 種に新
たに学名を与えた.これらの記載に用いた標本は，主 として1981年の12月から1982年の 3 月にかけて沖繩本 島，宮古島，池間島，石垣島の各地で下水溝，養魚 池, 溜池, および山間の清流などで採集したものであ るが，今回はそれらのらち，これまで記載しなかった Tanytarsus 属の 4 種, Orthocladiinae 亜科の 10 種, および Tanypodinae 亜科の 2 種, 計 16 種について主 として雄成虫の形態にもとういて種名を同定し，琉球 列島産のユスリカ科として追加した. さらに前回の Sasa and Hasegawa (1983) の報告において学名をつ けなかった Polypedilum 属の 3 種に新たに学名を与. えた.

今回記録した19種のうち12種は，従来記録された種 類に該当するものがなく，新種として学名を与えた. そのうちの Orthocladiinae の 1 種は, 雄の中脚の tibia の末端に後脚の tibia の末端と同じような櫛列 terminal comb をもち，それは従来知られている同重 科のユスリカにはみられない特徽であるため，これを 新属・新種として Okinawayusurika otsurui オウッ ル・オキナワユスリカと命名した．また，わが国には 末記録の Smittia pratorum と同定される種類の成虫 が多数探集された。 